\title{
علاقة أساليب المعاملة الوالدية بالاكتشاف المبكر لصعوبات التعلم لدى طفل ما قبل المدرسة
}

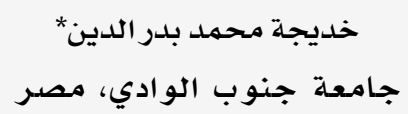

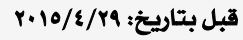

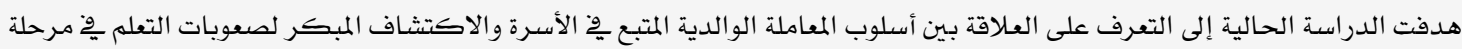

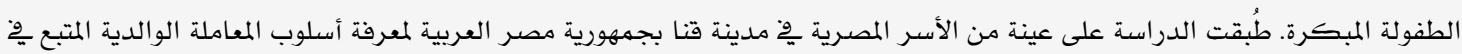

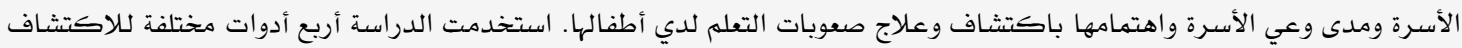

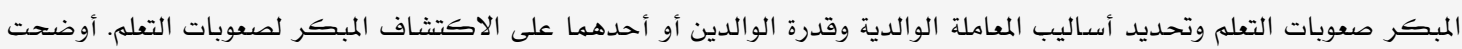

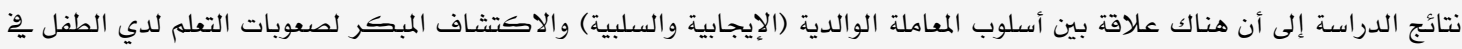

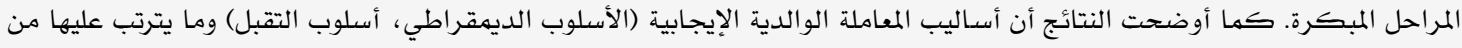

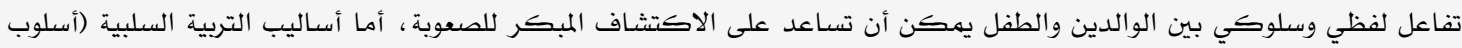

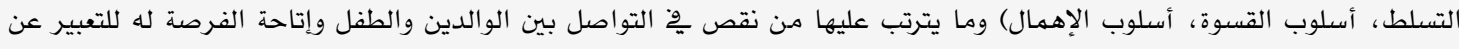

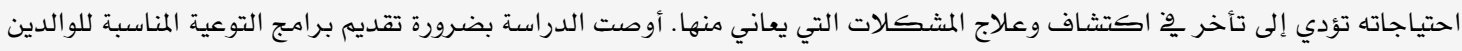
لاتباع أساليب التربية الإيجابية وتجنب الأساليب السلبية وِّونربية أطفالهه الكلمات المفتاحية: : أساليب المعاملة الوالدية، صعوبات التعلم، الاكتشاف المبكر، مرحلة ما قبل المدرسة.

\section{The Relationship between Parental Treatment Styles and Early Discovery of Learning Difficulties among Pre-school Children}

Khadeja M. Badr*

South Valley University, Egypt

This study aimed to explore the relationship between the parenting style and discovery of learning disabilities in early childhood education. The study used a sample of Egyptian parents to investigate the parenting style followed in the family. Also, the study investigated the family awareness and interest in the discovery and treatment of learning difficulties. The results indicated that there was a significant relationship between parenting style and discovery of child's learning difficulties in the early stages. The results also showed that there was a significant relationship between positive parenting styles and discovering of learning difficulties. However, there was a negative relationship between negative parenting styles and discovery of learning difficulties in early childhood. The study recommended the need to provide appropriate training and guidance programs of positive parenting and avoid the negative methods of raising children.

Keywords: parenting styles, learning difficulties, early detection, pre-school children.

\section{*khadejabadr@gmail.com}


كان الطفل يعاني من إعاقة سمعية مثلال، فعلى الوالدين بذل مزيد من الجهد لتعلهم لغة الإشارة

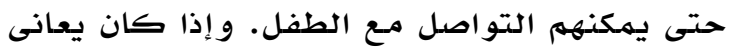

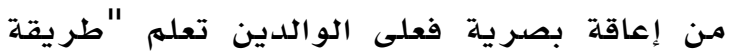

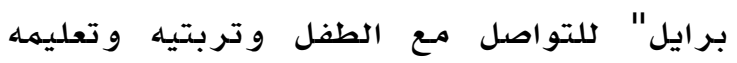

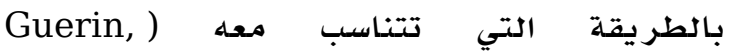
.(Gottfried, Oliver \& Thomas, 1994 ويشير مصطفى (r...r) إلى أن الأسرة قد تجهل

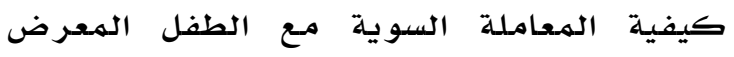

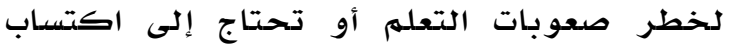

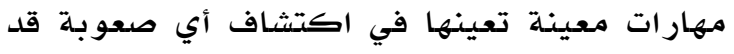

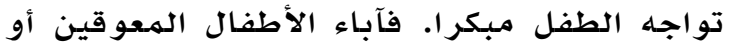
الهعرضين لخطر رعوبات التعلهم يحتاجون لاكتساب مهارات تعليمية لا يحتاج إليها آباء الأطفال الآخرون. وهذا يتطلب توعية الآباء

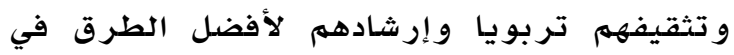
تربية الطفل والتي تساعدهم على الاكتشاف الهبكر لأي صعوبة يمكن أن يتعر ض لها. أساليب المعاملة الوالدية: تتباين أساليب معاملـة

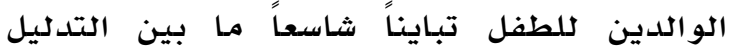
الزائد و القسوة المفرطة، وبين الحماية و الإهمال أو النبذ. و تعد هذه الأساليب أنماط متطر فة في

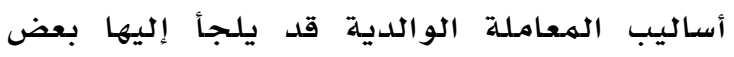

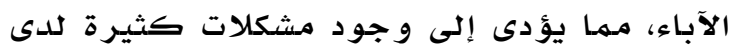

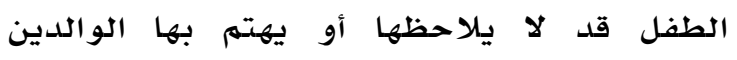

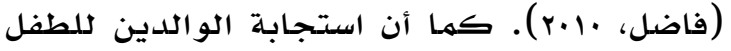

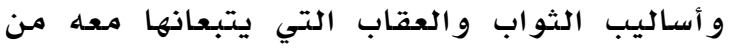

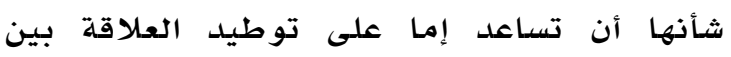
الوالدين والطفل أو على اهتزاز العلاقة بينهما

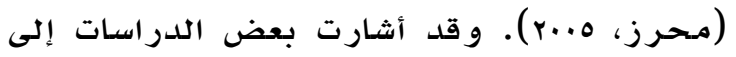
أن اتباع الأساليب الإيجابية في التعامل مـع الطفل

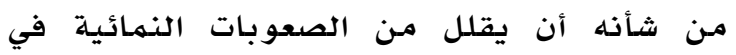

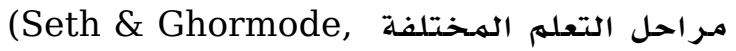

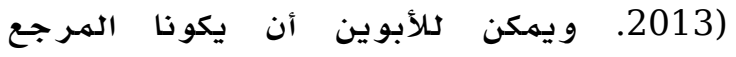
المعرفي و العاطفي الذي يستند إليه الطفل في لهني تشكيل نظرته الخاصدة إلى نفسه و والعالم من حوله. فإذا كانت الأسرة لديها طفل معوق ونظر الوالدان إلى إعاقته على أنها تبعث على خلى خيبـة الأمل، فإن الطفل غالباً مـا سينظر إلى إلى إعاقته
يتفق علمـاء التربية و علهم النفس على أن مـرحلة

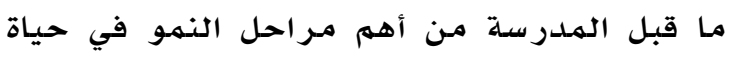
الطفل، و أن السنوات الأولى هي أساس لهن بناء

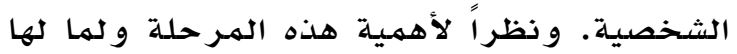

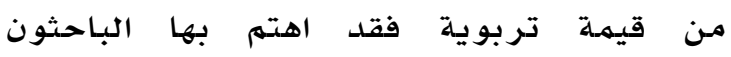

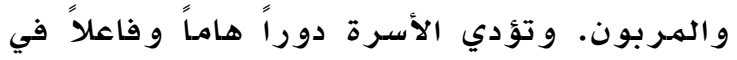

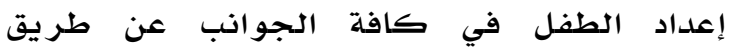
تزويده بالقيه والاتجاهات و المعارف و المهارات

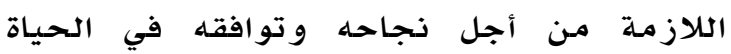
الاجتماعية والأكاديمية. و ويعاني بعض اجله الأطفال

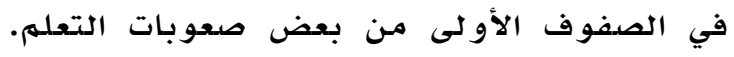

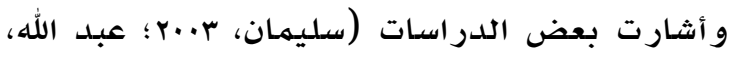

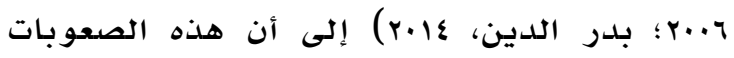
ليست بجديدة على الطفل و إنما هي نتيجة

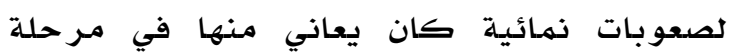

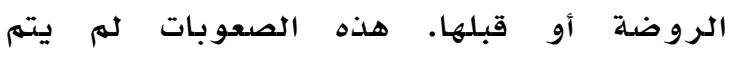

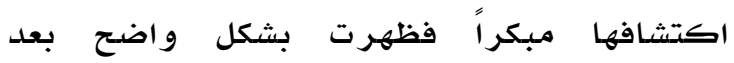

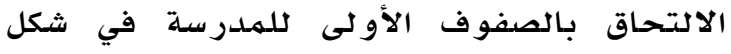
صعوبات تعلهم، و عليه فإن أساليب معاملـة الوالدين الدوين

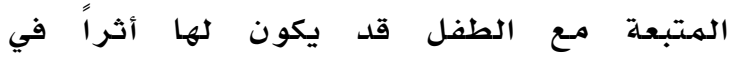
الاكتشاف المبكر لهذه الصعوبات التي يمكن أن يتعر ض لها الطفل.

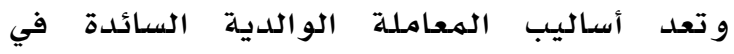
الأسرة إحدى مؤشرات الحكمم على تقدم الأسرة السراه

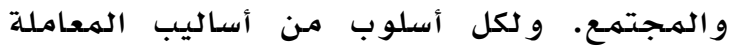

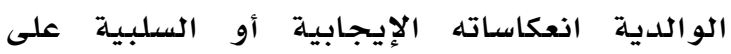

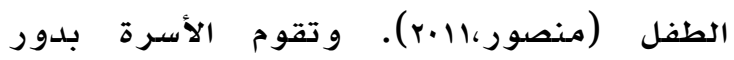
أسـاسي وهام في تربية الطفل و تعليمـه و إكسابه

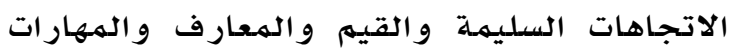
اللازمة لنهموه من خلال ضبط سلوكهه عن طريق

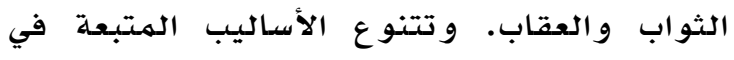
الأسرة ما بين أساليب صحيحة وخاطئة و ذلك ولك

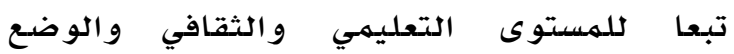
الاجتماعي و الاقتصادي، وجنس الطفل و وترتيبه

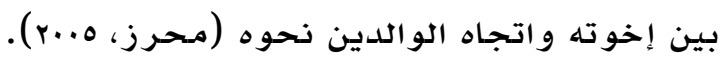
و يري بعض الباحثين أن عملية توجيه الطفل

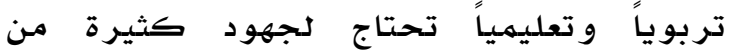

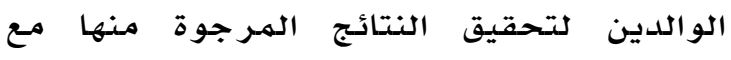
الوضـع في الاعتبار قدرات الطفل و إمكاناته. فإذا 
في حين أثار فايد (r..v) إلى أسلوبين هما أسلوب التسلط و أسلوب التقبل. بينها أثار التهار

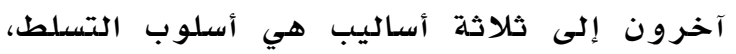

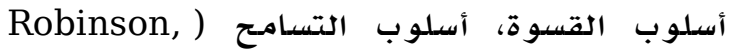
.(Mandleco, Olsen \& Hart, 1995

ويعد الأسلوب الديمقراطي أحد الأساليب

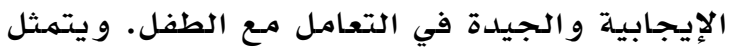

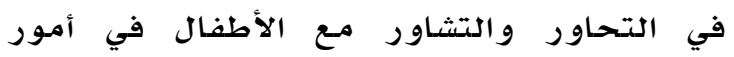
تخصهم أو تخص الأسرة، والتعبير عن آرائهم

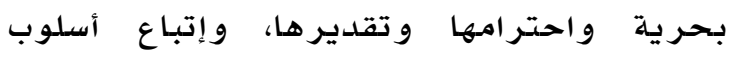

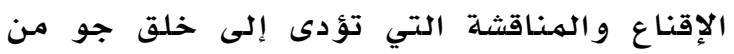

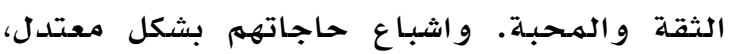

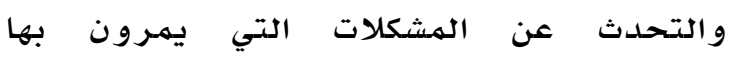
و تعليههم كيفية حلها. و هذا يؤدى إلى شعور

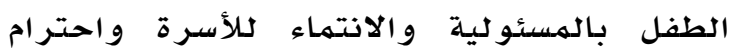

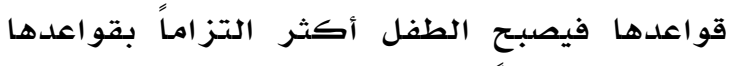

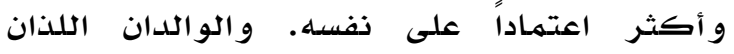

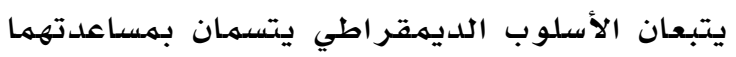
لأطفالهم في مختلف الجوانب، وتشجيعهم

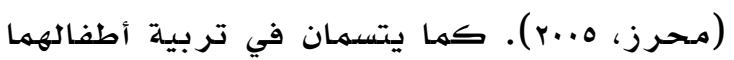

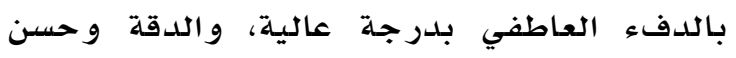

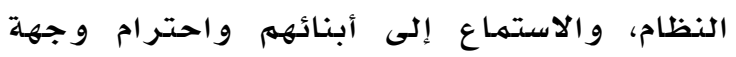
نظرهه. وهذا يؤدى إلى نهو الاستقلالية لدى لدى الدئي

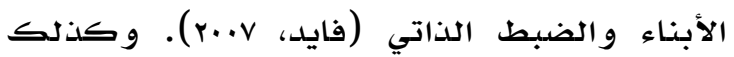
فإن أسلوب التقبل هو أحد الأسـاليب الإيجابية

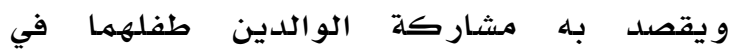
الأنشطة و المناسبات التي تخصله و التعبير اللفظي

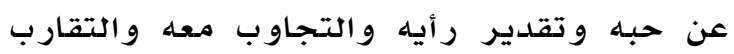
منهله والفخر بتصر فاته.

ويقصد بالتسلط المنـع والرفض الدائم لرغبات الطفل حتى ولو وانت صائبة و ومشروعة. و يتمثل في فرض قيود متشدل فيدة على الطفل والتحكم به من الأم أو الأب أو كليهما، يظهر فيودر

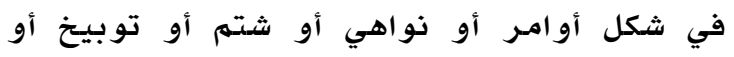

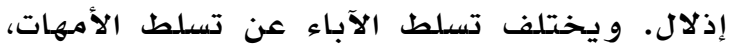

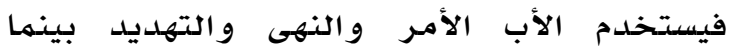

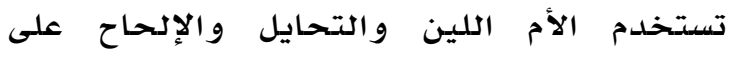
الطفل. ويؤدى الأسلوب التسلطي إلى نتائج سلبية منها ضعف شخصية الطفل، ضعف الثقة الثقدي بالنفس، الشعور بالدونية، الخوف من السلطة،
نفس نظرة والديه. أما إذا تعامل الوالدان مـع إعاقته بواقعية وحاولا إيجاد الطرق المناسبـة

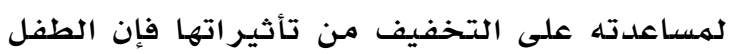

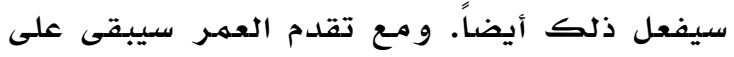

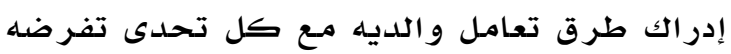
الإعاقة في كل مرحلة عمرية (مصطفى، ب...r).

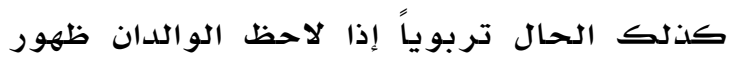

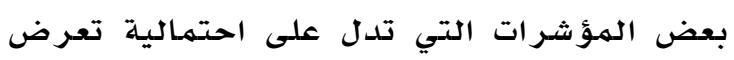

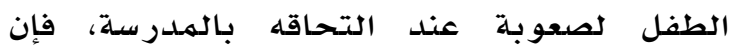

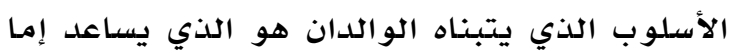

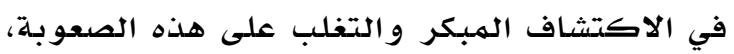
أو لا يلاحظها الوالدان فتستهمر وتتفاقم ثم تظهر الاهر في شكل او صعوبات أكاديمية عند التحاقه بالمدر سلة

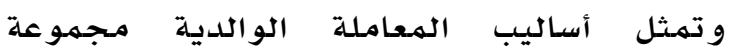

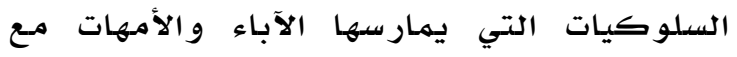

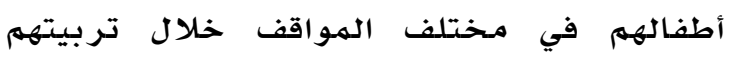

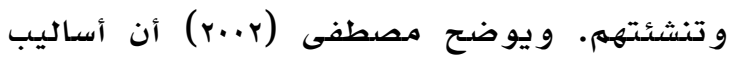

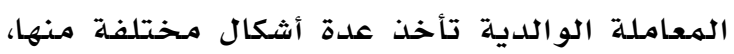

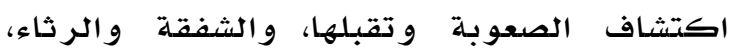
إنكار الصعوبة، إهمال الطفل و ونبذه أحياناً،

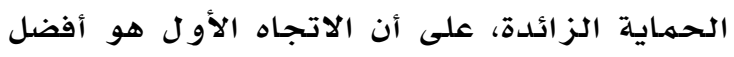

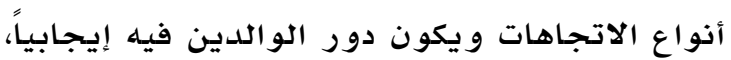

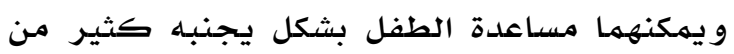
المشكلات التي قد تؤدى إلى صعوبات في التعلم.

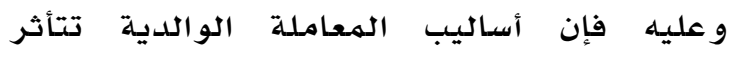

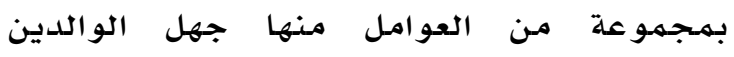

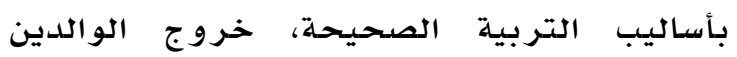
للعهل، كثرة الأعباء المنزلية لئه على الأم.

و تتنوع أساليب المعاملة الوالدية وتختلف تبعاً

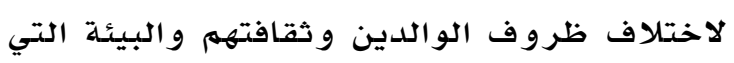

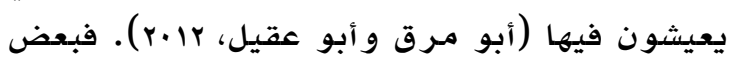

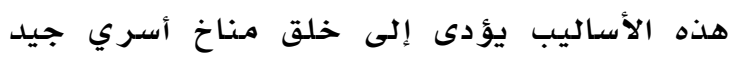
يساعد في التحصيل الجيد والتفوق الهئ الدراسي،

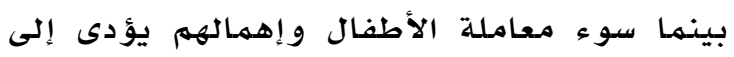

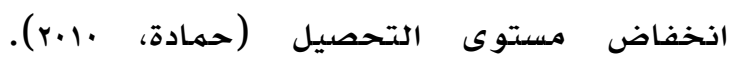

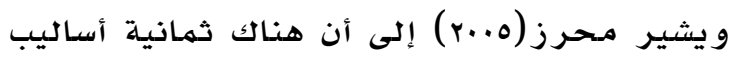

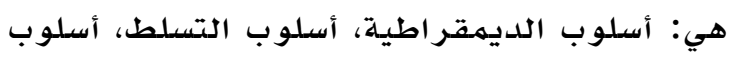

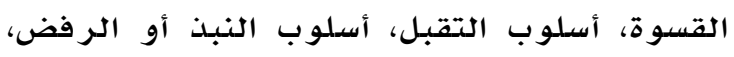

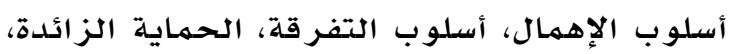


الاهتمام بتلك الفئة من الأطفال. و مها يزيد من

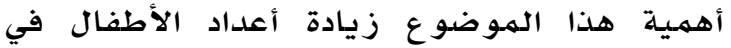

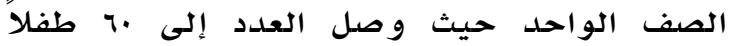
وطفلة أو أكثر في بعض الأحيان، مهما زاد العبء

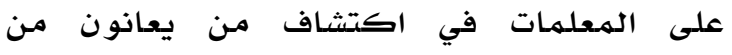

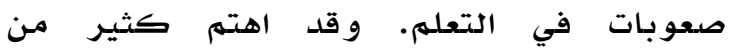
الباحثين بمجال صعوبات التعلهم ولكن لا يزال

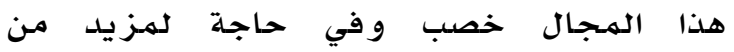

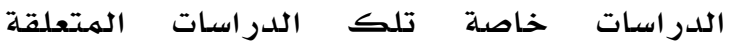
بصعوبات التعلهم في مرحلة مـا قبل المدررسة.

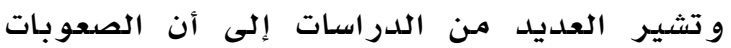
التي يعاني منها الأطفال في المرحلة الابتدائية

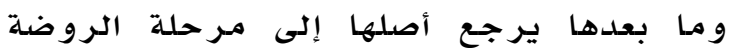

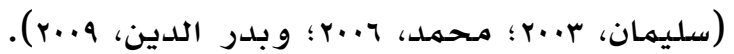

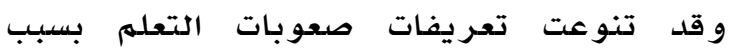

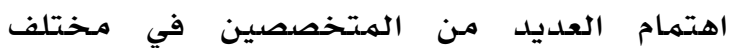
التخصصات كالطب النفسي و الفسيولوجي والأعصاب والنطق والكلام. ويشير مصطلح صعوبات التعلم إلى مجموعة غير متجانسلة مـن

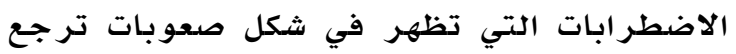
إلى الكيفية التي تهم بها اكتسـاب الههارة و أنها داخلية المنشأ و وترجـع إلى خلل وظيفي في

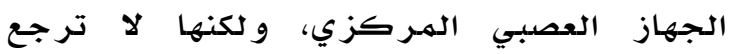
لقصور حسي أو تأخر عقلي أو اضطر اب انفعالي

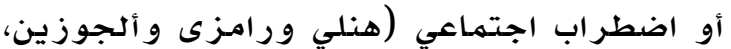

$$
\text { . (r...) }
$$

و تصنف صعوبات التعلهم إلى نوعين رئيسين هما

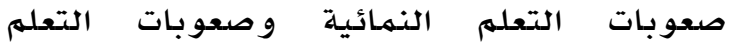

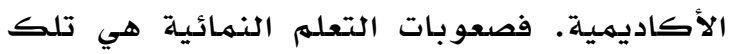

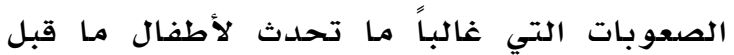
الهمدرسة وهي صعوبات تتعلق بالانتباه والإدراك، والتفكير، والتذكر، اضطر ابات اللغة الشفهية. و أي قصور في أي مهارة من هذه المهارات يؤثر

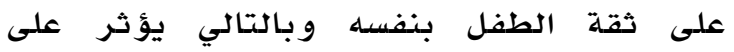
مستواه الأكاديمي. ووقد أشارت دراسـة الشخص،

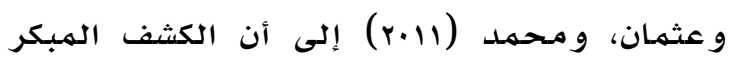

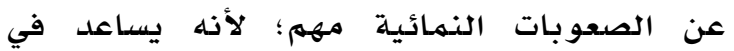
تقديم المساعدة والإجراءات الوقائية في الوقت

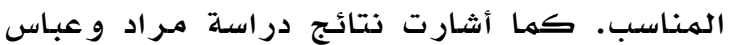

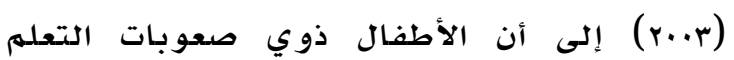

الطاعة العمياء فلا يمكنه أن يصبـح قائداً بل يكون

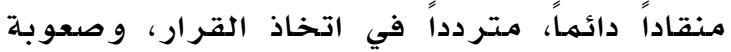
معرفة الصواب من الخطأ، كما يؤدى إلى تسيب الديب الطفل في أداء الأعمال و الواجبات، و ومهمارسة

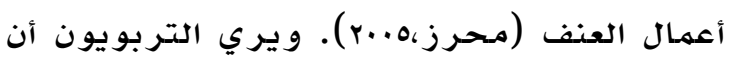
هذا الأسلوب يتصف بانخفاض درجة الدفء العاطفي، إذ تتصف انفعالات الوالدين بالحدة فهما

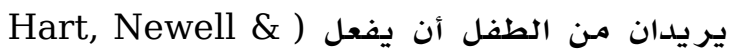

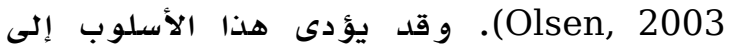
العدو انية و عدم التعاون والخوف من العقاب مـما يجعله لا يقدم على أداء عمل قد يفشل فيه خوفاً من العقاب.

أما أسلوب الإهمال فيقصد به ترك الطفل دون رعاية واهتمـام أو تشجيع على السلوك الهربوغ غوب

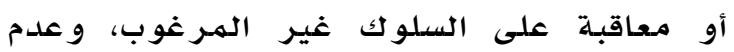
الاهتمام بتوجيه الطفل أو التحدث معده. ويبدو الإهمال في أشكال متعددة مثل إهمال الهمال الحاجات الفسيو لوجية و النفسية و التغاضي عن التصر فات السيئة لكلأطفال و عدم مكافئة السلوك ولك الجيد. كما يبدو في ترك الأطفال وحيدين في المنزل،

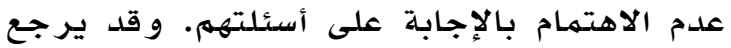

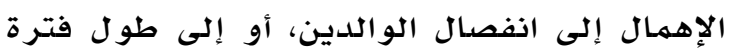

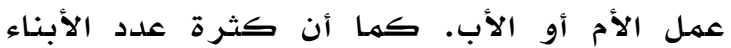

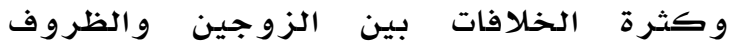
الاقتصادية السيئة كلها عوامل تؤدى إلى إهمال

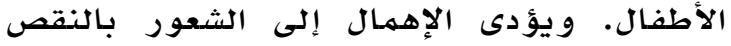

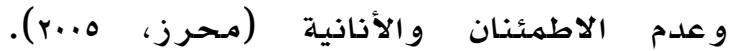
ويتصف الوالدان اللذان يتبعان هذا الأسلوب بتدني مستوى الدفء العاطفي لديهم وانشغالهما بأمور هما الذاتية دون الاهتمام بالأبناء ( Wenar

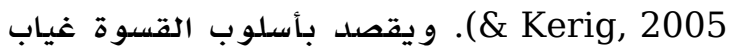

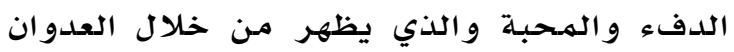
على الطفل واستخدام العقاب البدني أو اللفظي

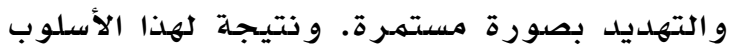

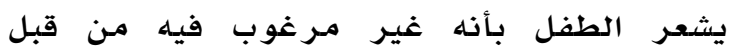

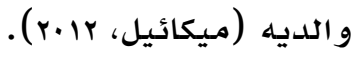

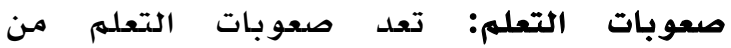

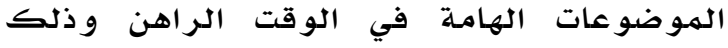

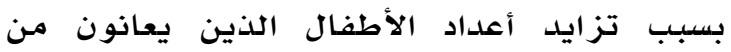

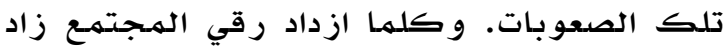


الطبيعية ويتأملها و يفكر فيها، ويزداد دقة ونضـج

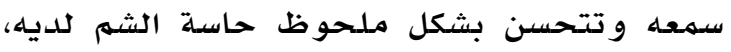
فيكتسب الكثير من الخبر ات العقلية المعرفية التي تزوده بحصيلة من المعلومات فيصبح قادرا

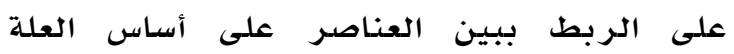

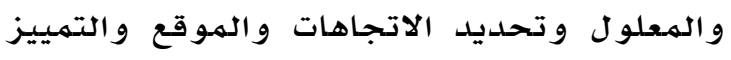
بين الهتشابهات مـن الأشياء و الحروف. و وإذا كان

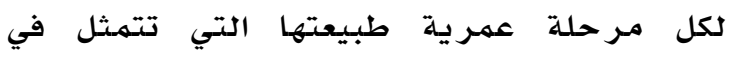

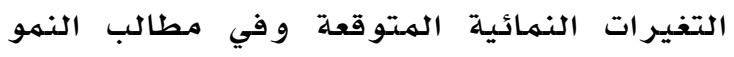

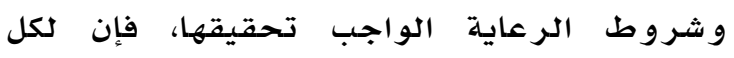

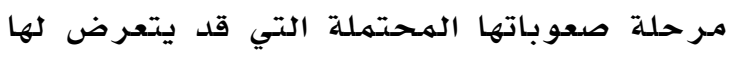

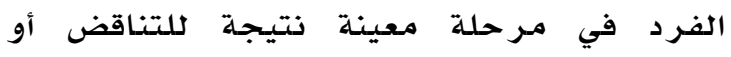
اختتلال التوازن بين طبيعة التغيردير ات النهمائية

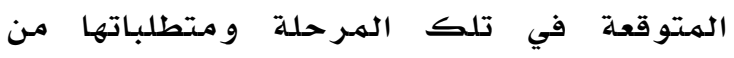
الر عاية و الضغوط المفرو ضوضة على الطفل.

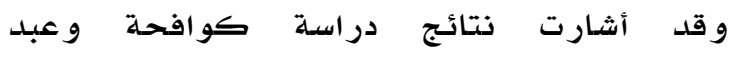

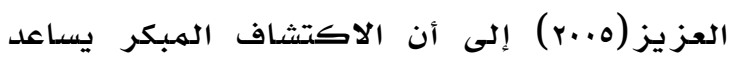
في تقليل المشكلات التي قد الاتل تنتج عن عن عدم

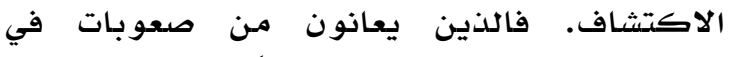
القراءة ويتمم اكتشافهم مبكراً و علاجهم يكون

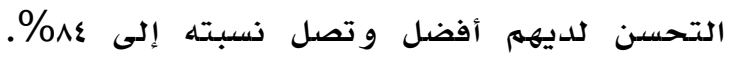

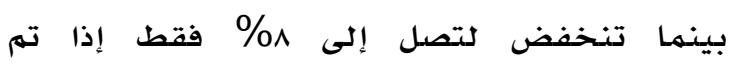
اكتشافهم وهم في الصف السادس الابتدائي.

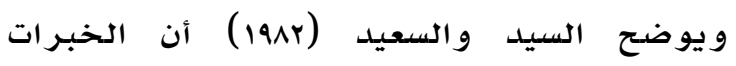

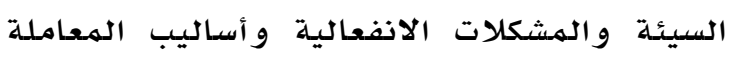

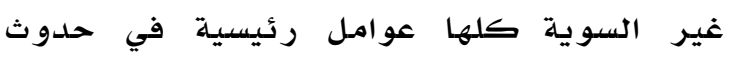

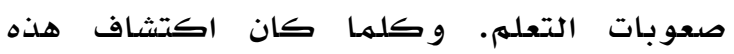

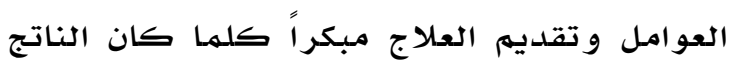

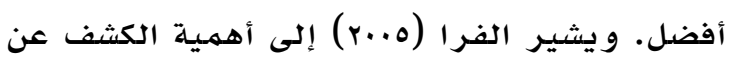
الجوانب النمائية في مرحلة ما قبل المددرسة الأن

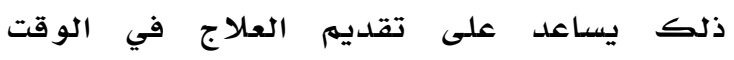
المناسب لكلأطفال الذين يعانون من مشكلات في في النهو تؤثر على استعدادهم في الهدرسة واتخاذ إجراءات وقائية تحول دون تفاقم آثارها السلبية الثرية في الهستقبل. ويتمثل الاكتشاف الهبكر في فوليك الكشف عن صعوبات تتعلق بالجوانب النهمائية

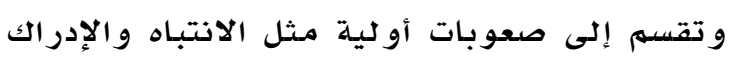
والذاكرة و صعوبات ثانوية مثل التفكير و الككلام و الفهم و اللغة الشفهية وقد توجد للدى الطفل في
النمائية في حاجة لرعاية فعلية و أساليب تربوية

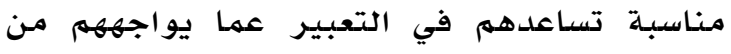

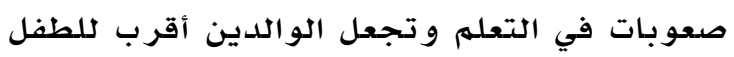

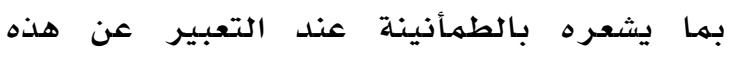

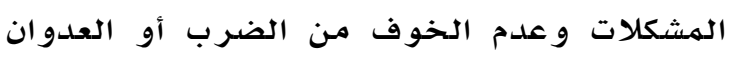
اللفظي.

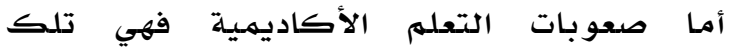

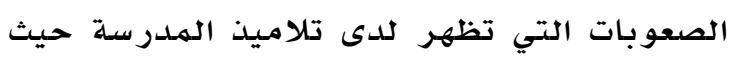

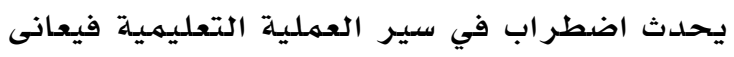

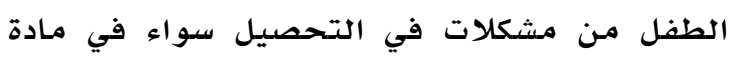
واحدة أو أكثر، فعندما يظهر الطفل قدل فلدرة كامنسة على التعلهم ويكون تحصيله الأكاديمي اوله

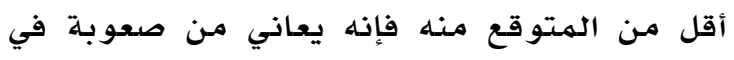

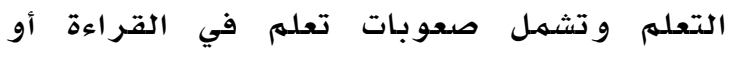

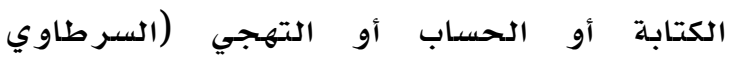

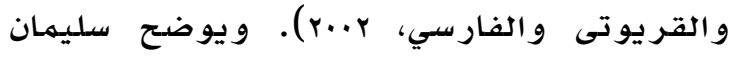

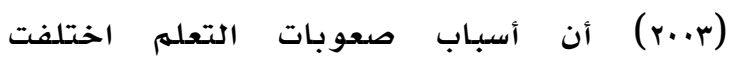

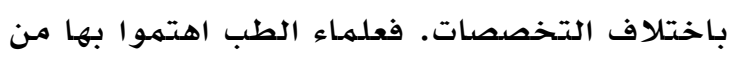
زاوية الأسباب العضوية و الفسيو لوجية باعتبارها

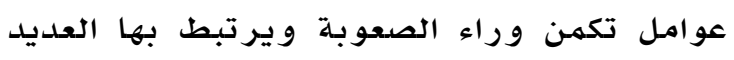

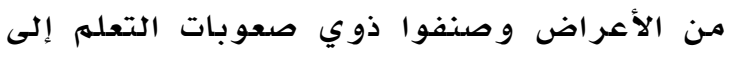

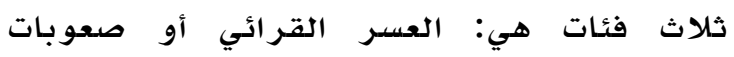

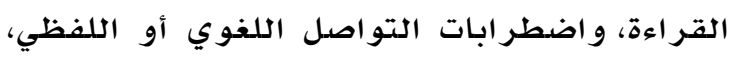
و مشكلات التكامل البصري الحركي.

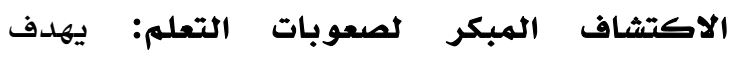
الاكتشاف المبكر إلى التعرف على الأطفال الذين ينحرف نموهم عن نمو الأطفال العاديين بهدف أخذ خطوات تساعد على التقييم الشامل

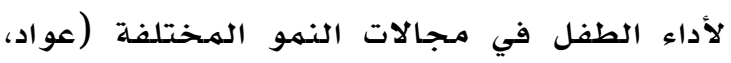

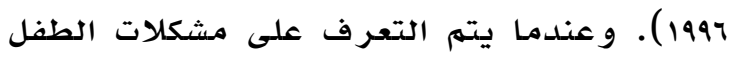
مبكراً فإن الفشل المدررسي المتوقع أن يزداد

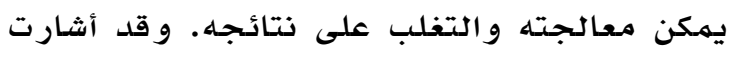

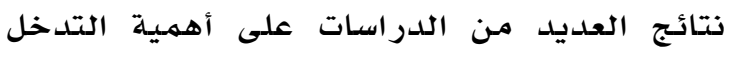
المبكر وأثره في التغلب على ما يمكن أن يعانيه

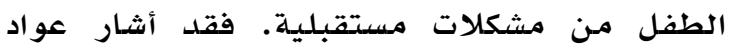

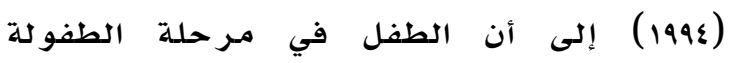

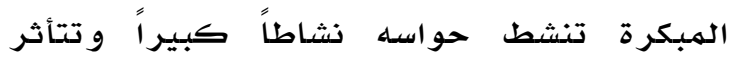
الهمركات الحسية لديه فيدرك الفوارق بين

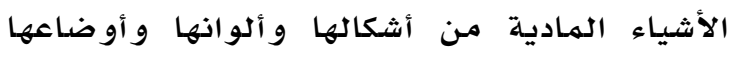
و أصواتها و وروائحها، كها يتعرف على الظواهر 
يعاني منها الطفل في هذه المرحلة نتيجة عدم إتاحة الجو الملائم للتفاعل مـع الطفل والتعبير عن حاجاته ورغباته. و ومن خلال خبرة الهبرة الباحثة

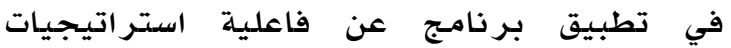
التربية الإيجابية في تنمية تقدير الذات لدي لدير الأطفال ذوي صعوبات التعلم في دراسـة سابقة

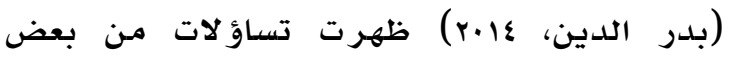
الوالدين و المعلمات عن عواقب عدم إتباع أساليب

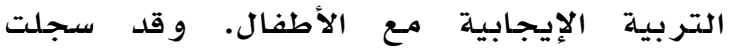

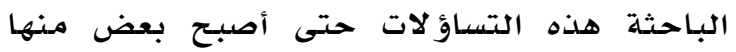
مدحوراً للدر اسلة الحالية.

من هنا ظهرت مشكلة البحث في مححاو لة سد هذه

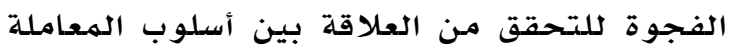

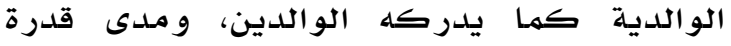

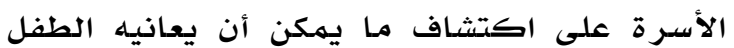

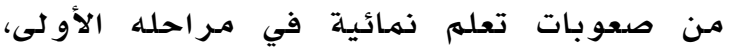
و بالتالي التنبؤ بما يمكن أن يعانيه من صعو بات تعلهم أكاديمية في مراحل تالية. و وبذلك فإنه يمكن تحديد مشكلة البحث في السؤال التالي: ما

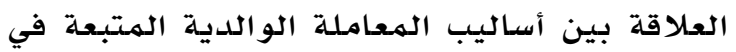

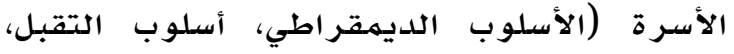
أسلوب التسلط، أسلوب القسوة، أسلوب الإهمال) و قدرة الوالدين على اكتشاف ما يعانيه الطفل من مظاهر لصعوبات التعلهم في مرحلة ما قبل

تظهر أهمية البحث في التأكيد على الدور الذي يقوم بـه الوالدين في تربية الطفل و الذي يعتهد بشكل كبير على الأساليب التي يتبعونها و أثرها في اكتشاف ما يمكن أن يعاني منه الطفل مـن مشكلات. هذه الأساليب بلدورها لها أثر كبير في

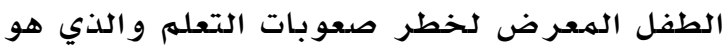
في أمس الحاجة إلى معاملة خاصدة من الوالدين حتى يتسنى لهم الوقوف على المشكلات التي يعاني منها. وبالتالي فإن البحث يهدف إلقاء

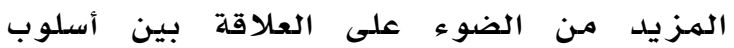

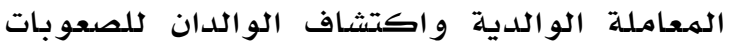
التي يمكن أن يعاني منها الطفل. و مهما يؤكد

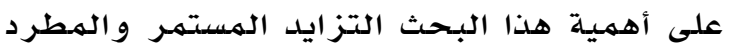

ثلاثة مجالات هي النمو المعرفي،والنمو اللغوي، و نهو الههار ات الحركية. و أخيراً فإن تشخيص الصعوبة وتقديم العلاج يحتاج إلى والدين أو معلمين معدين و مددربين لتطبيق الطرق الصحيحة لاكتشاف الصعوبات

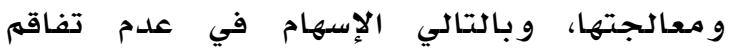

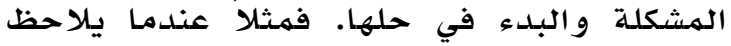

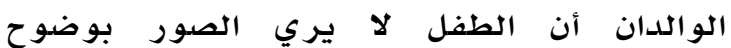

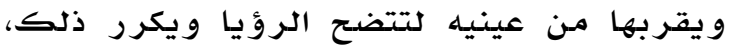
فعلى الوالدين الذهاب مباشرة لطبيب العيون لقياس النظر و اتخاذ الإجر اءات اللازمـة، فالوالدان هما اللذان اكتشفا هذه المشكلة. كذلك الكرال الحسال عندما يلاحظ الوالدان أن الطفل لا يتهكن من التمييز بين الأصوات أو الصور المتشابهة أو أن أن أنها

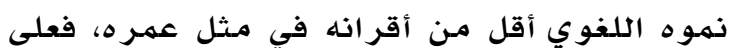
الوالدين الذهاب مباشرة لمتخصص في صعوبات الهري

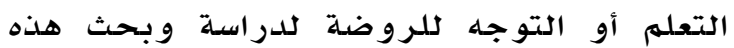

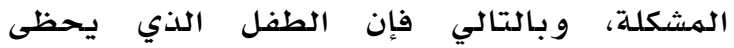
بالاهتمام من أسرته وومتابعتها له يمكن أن يتم اكتشاف الهشكلات التي يعاني منها مبكر أ. أما إذا لها كانت الأسرة لا تهتم بالطفل و لا تمنحه الفر صدة الكافية للتعبير عن رأيه و مشاعره أو للتفاعل معهد فإنها ربما لن تتمكن من اكتشاف أيلة مشكلة يمكن تو اجهه. مشكلة البحث تناولت العديل من الدراسـات أساليب المعاملة الوالدية المختلفة و علاقتها بتوافق الطفل الذاتي و الاجتماعي في مـرحلة الطفولة، دون التطرق إلى أثر هذه الأسـاليب على علاقة الطفل بوالديه أو قدرتهم على اكتشاف ما يمكن أن يواجـه الطفل من مشكلات أو مظاهر لصعوبات التعلهم

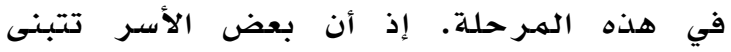

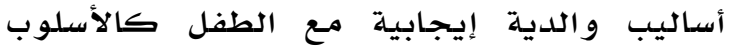

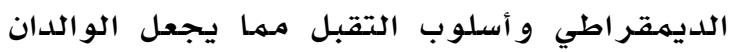
قريبان من الطفل و على تواصل و تفاعل دائم معهد و بإمكانهما اكتشاف أي مشكلة قد يتعرض له لها. بينها تتبنى أسر أخرى بعض الأسـاليب السلبية

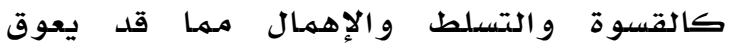
إمكانية اكتشاف الوالدين لأي مشكلة أو صعوبة 
مصطلحات البحث

تبنت الباحثة التعريفات الإجرائية التالية:

أساليب المعاملة الوالدية: هي تلك الأساليب التي يتبعها الوالدين في تربية أبنائهم سواء سواء

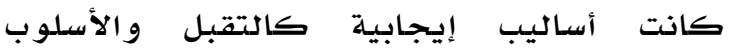

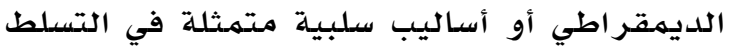

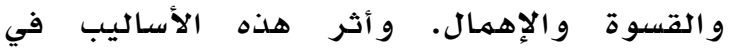
اكتشاف الوالدين المبكر لأي صعوبة والهية يمكن أن يو اجهها الطفل.

الاكتشاف المبكر: هو قدرة الوالدين على اكتشاف ما يعانيه الطفل من صعوبات في التعلهم في مـرحلة الروضة سواء في الجانبين اللغوي و والعددي.

مرحلة مـا قبل الملدرسة: هي تلك المـرحلة التي

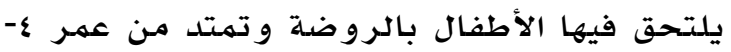
17

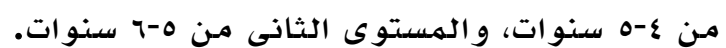

\section{منهج البحث}

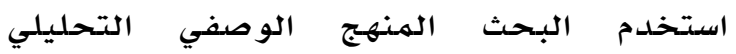

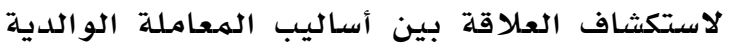

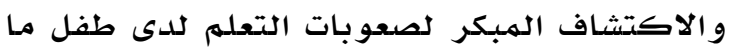

\section{قبل الهمدرسة. \\ حدود البحث}

تم اختيار عينة البحث الحالي من أطفال ثلاث روضات في مدينة قنا بجمهورية مصر العربية بية العرية

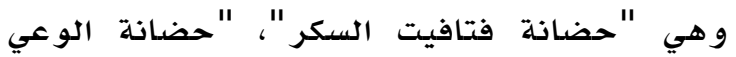

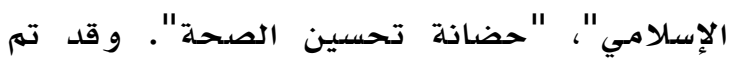

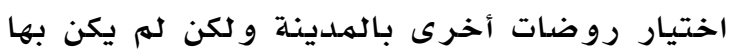
أي طفل حصل على درجة أقل من ل0 في بطارية الههارات قبل الأكاديمية. وقد تم تطبيق اخدي اختبار

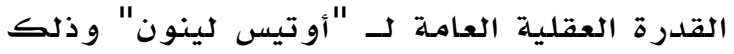
لاستبعاد الأطفال الذين لديهم قدرات الدهات عقلية أقل

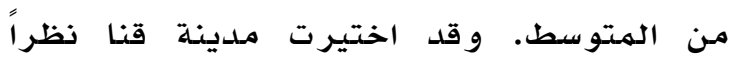

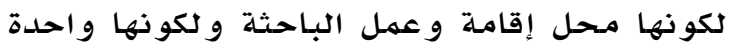

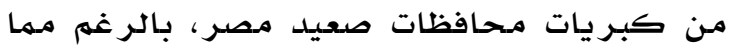

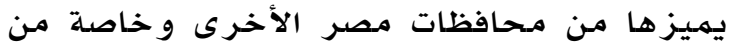
الناحية الاقتصادية والتعليمية. كما تهم تطبيق مهيق
لصعوبات التعلهم التي يعاني منها تلاميذ المـدراس و التي تمتد جذورها إلى صعوبات في مرحلة

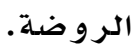

كما تبدو أهميلة البحث فيما يقدمه من مساعدات

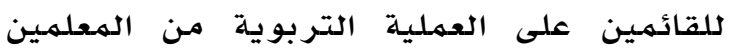

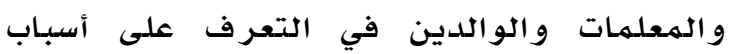
نفسية جديدة قد تساعد في الاكتشاف المبكر لصعوبات التعلهم والانعكاسات الإيجابية والسلبيية

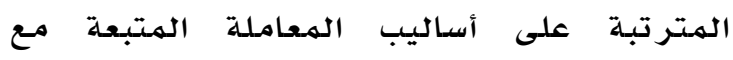

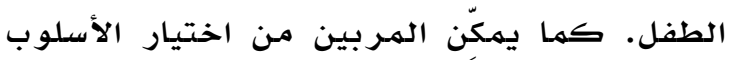
الهناسب الذي يمكنهم من خلاله متابعة أطفالهم.

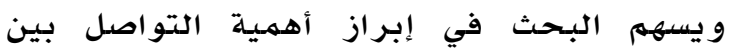

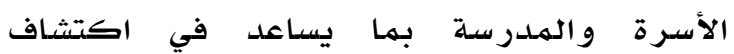
المشكلات التي يمكن أن تواجه الطفرة الطفل مبكراً.

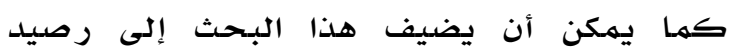

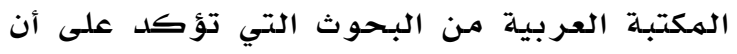

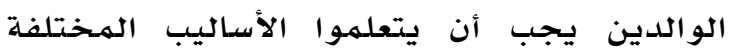

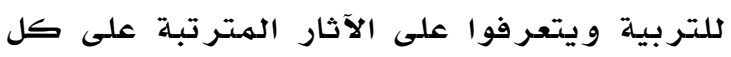
منها ويختاروا منها ما يتناسب مـع مـا يتطلعون إليه من جيل المستقبل. فروض البحث

في ضوء العرض السابق لأساليب الهعاملة الوالدية و علاقتها بالاكتشاف المبكر لصعو لصوبات

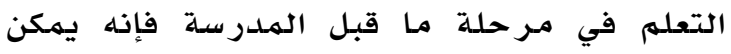
تحديد فروض البحث فيما يلي:

ا. توجد علاقة ارتباطية موجبة ذات دلالة

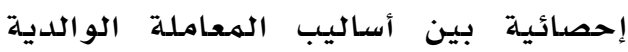

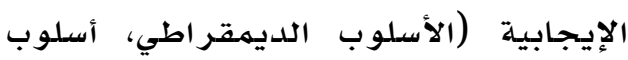

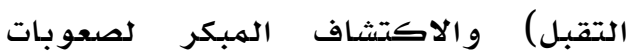
التعلهم في مرحلة مـا قبل المدررسة. r. توجد علاقة ارتباطية سالبة ذات دلالة إحصائية بين أساليب الهعاملة الوالدية الدية السلبية (أسلوب التسلط، أسلوب السينة القسوة،

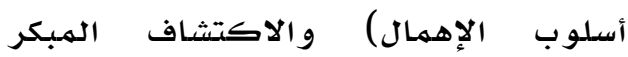

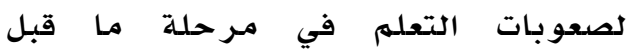

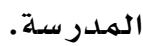


الوعي أو الإدراك الفونولوجي، و التعرف

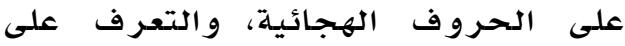

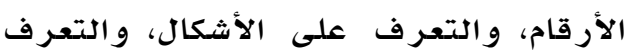

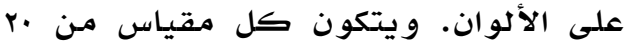
عبارة فرعية تعكس ما يصدر عن الطفل من سلوكيات أو مظاهر سلوكية تهرة تعد بمثابة مؤشرات لصعوبات التعلهم. فالطفل الذي يحصل على درجة أقل مـن لهو في فئل

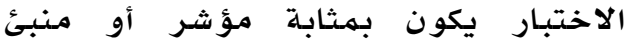

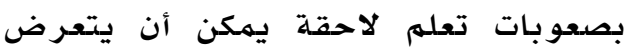
لها. تراوحت قيهم الصدق التلازمي بين

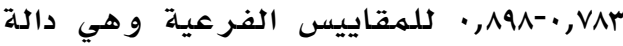
عند مستوي ا.,.• و تراوحت قيهم ت الدالة على الصدق التمييزي عند مقارنة الأطفال

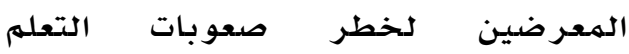
بالروضدة وأقرانهم العاديين حيث كانت ن=

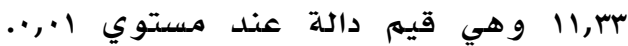
لحساب الثبات استخدمت طريقة التجزئة

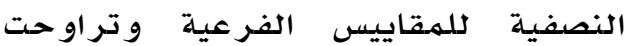

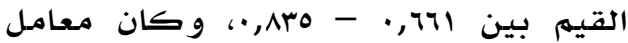

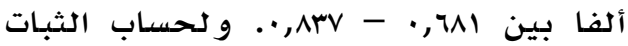
في البحث الحالي تم استخدام طريقة التجزئة النصفية فكان معامل الثبات بعد

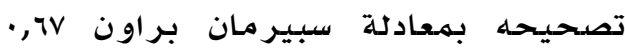
و هو معامل ثبات مقبول.

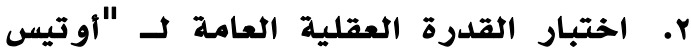
لينون": تم تطبيق اختبار القدرة العقلية

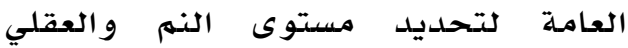

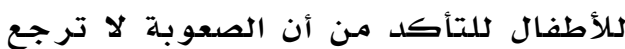
إلى ضعف القدرات العقلية ولاستبعاد

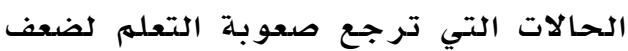
القدرات العقلية. أعد هذا المقياس أوتيس

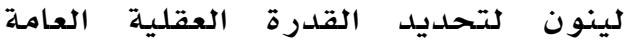

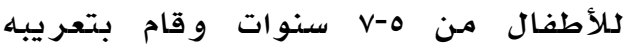
و إعداده للبيئة المصرية كلاد كامل (199V).

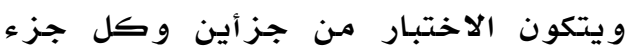
يحتوي على مجسموعة مـن الفقرات تشهمل

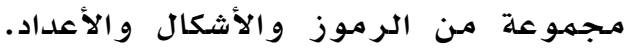

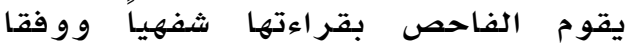

البحث خلال شهر يونيو rابr واستغرق تطبيق الأدوات وجهـع البيانات أربعـة أسـابيع متصلية.

\section{عينة البحث}

انقسمت عينـة البحث إلى مجمهو عتين كالآتي: - عينة البحث الاستطلاعية: و هدفت إلى تقنين

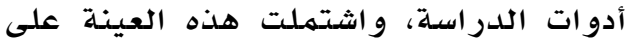

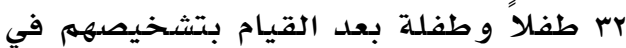

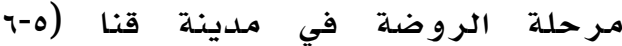

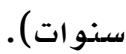

- عينة البحث الرئيسية: تم اختيار عينة

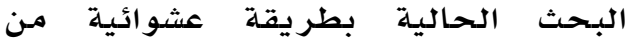

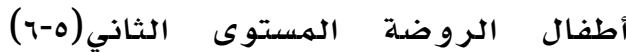
سنوات المعر ضون لخطر صعوبات التعلهم وأولياء

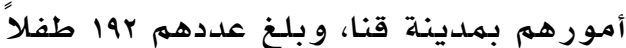
موزعون على أربع روضدات. وطبقت بطارية المهارات قبل الأكاديمية لأطفال الروضـة، واختير الأطفال الحاصلين على الى اله درجات أقل من له على بطارية اختبارات الههارات قبل الأكاديمية والذين هم معرضون لخطر صعوبات التعلهم والذين

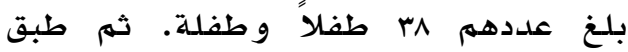
اختبار القدرة العقلية العامـة لأوتيس

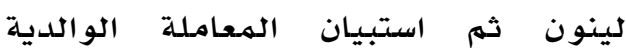
و مقياس الاكتشاف المبكر ل الأطفال الرووضة من قبل الو الدين.

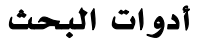

للتحقق من صحة فرضي البحث استخدمت

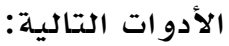

ا. بطارية اختبارات لبعض المهارات قبل

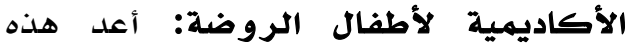

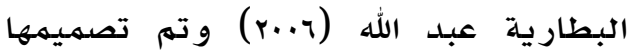
لأطفال الروضدة بهدف التعرف على قصور المهارات قبل الأكاديمية. ويتمم من خلالها لها التعرف على الأطفال الذين توجد لديهم

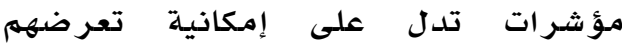
لصعوبات تعلم أكاديمية فيما بعد. تتكون البطارية من خمسة مقاييس فرعية هي: 
أما استبيان تحديد أسلوب المعاملة الوالدية كما

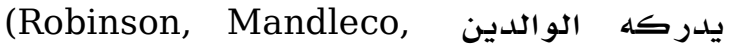
Olsen \& Hart, 1995)

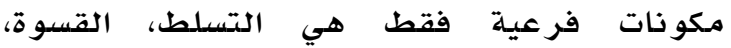
التسامـح. حيث يطلب اختيار معدل عدد المرات

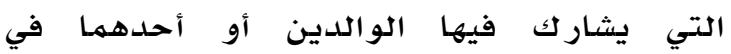

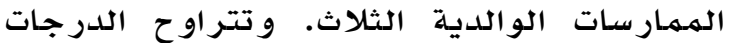
من "أبدا" إلى "دائماًا" على مقياس من الو 7 نقاط.

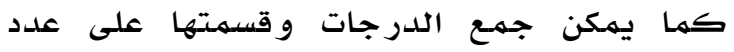
الأسئلة في نهاية كل جزء ليحصل الوالدين على متوسط الدرجات والذي يمثل النتيجة الإجمالية لتلك الفئة، و الذي يشير أعلى الدرجات فيها إلى لى له

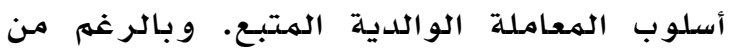

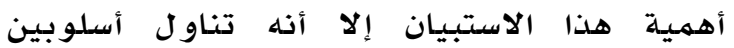

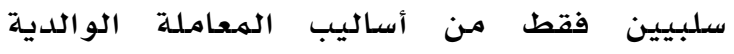
السلبية و أسلوب واحد فقط من أساليب المعاملة

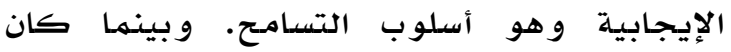

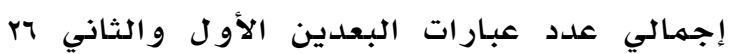

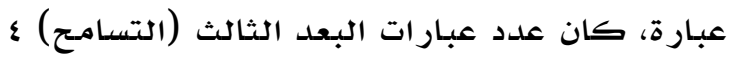

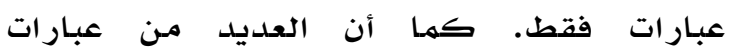

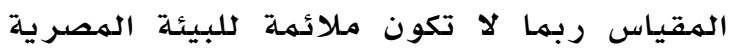

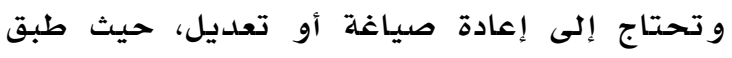
المقياس في البيئة الأمريكية.

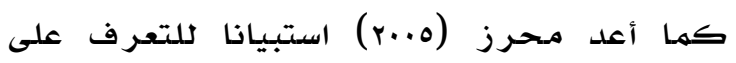

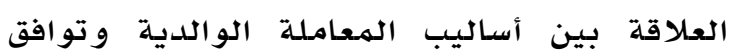
الطفل الاجتماعي والشخصي في رياض الأطفال

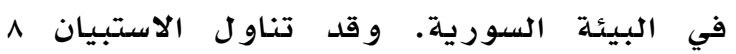

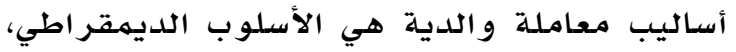

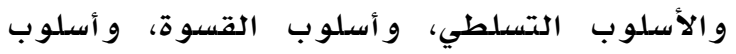

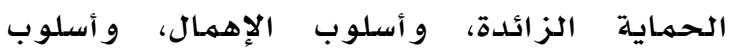

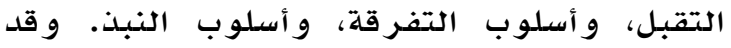

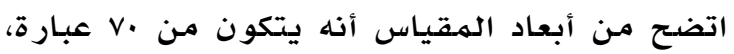

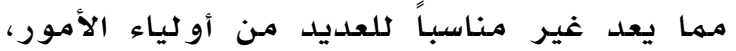

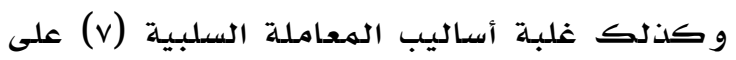
الأساليب الإيجابية (1)، حيث تضمن الإبه الاستبيان أسلوب إيجابي وحيد و هو الأسلوب الديهقر اطي. وبالتالي فقد ظهرت الحاجة إلى تصميم استبيان يكون مناسباً في طبيعته و صياغة أبعاده و عباراته

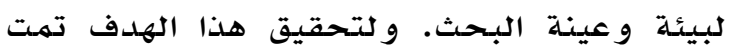
مر اجعة الدراسات التي تناولت أساليب الهعـاملة
للزمن المحلدد لكل جزء ويطلب من من المفحوص وضع دائرة على الإجابة

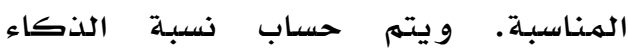
بإعطاء درجة لكل إجابة صحيحة ثم إهم

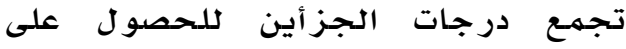
الدرجة الكلية الخام و بهعرفة عمر الطمر الطفل يتم تحويل هذه الدرجة إلى نسبة ذهاء

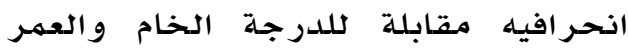

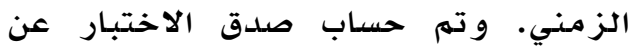

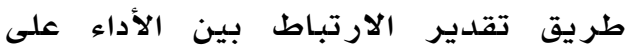

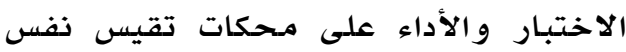

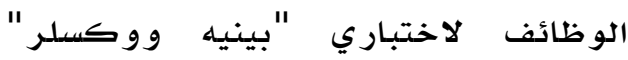
لأطفال الروضدة وكان معامل الارتباط لواطيان

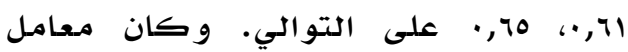
الثبات بطريقة التجزئة النصفية و وبعد ولهد

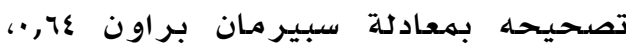

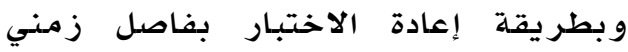

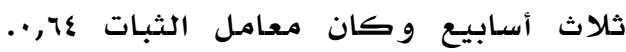
وتم حساب ثبات الاختبار في البحث الحالي بطريقة التجزئة النصفية وكان

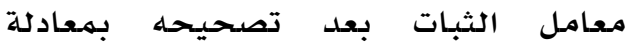

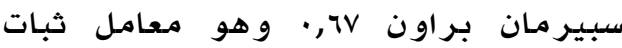

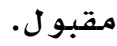

r. استبيان أساليب المعاملة الوالدية كما كاندان يدركها الوالدان (من إعداد الباحثية):

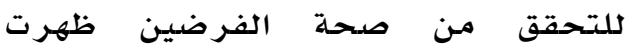

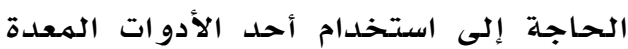

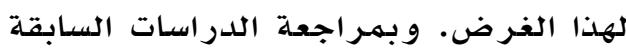
والهقاييس ذات العلاقة وجد أن غاجهراتهيتها

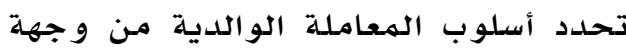
نظر الأبناء، وليس كهما يدركه الوالدين

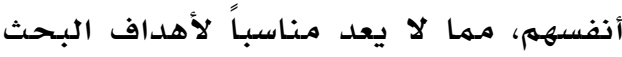

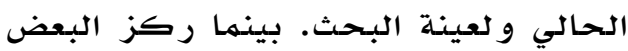

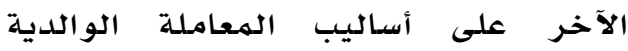

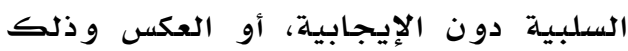

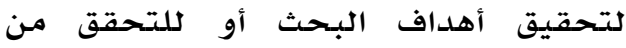

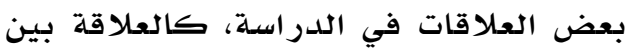

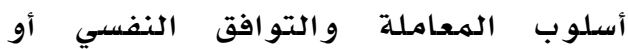
الإنجاز لدى الطفل. 
إلى r (لا يحدث مطلقاً - يحدث أحياناً - يحدث

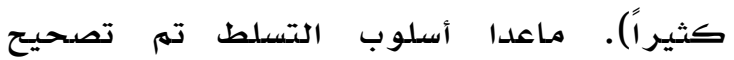

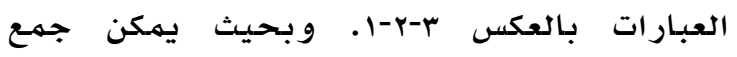
الدرجات وقسمتها على عدد العبارات في نهاية كل بعد للحصول على متوسط الدرجات لكل الدل الدئل

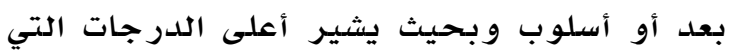

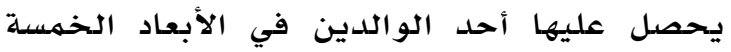

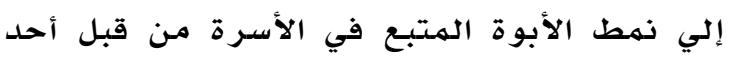

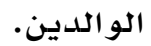

صدق الاستبيان: تم عرض مفردات المقياس

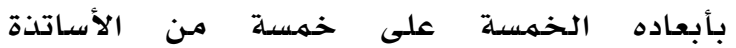
المتخصصين في علم النفس التربوي وصعوبات التهات التعله كمحكمين لمدى ارتباط ودقة العبارات الهين المستخدمة في المقياس وانتماء العبار ات للأبعاد التهاد

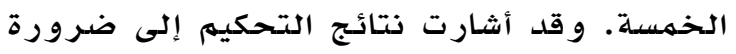

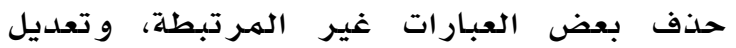

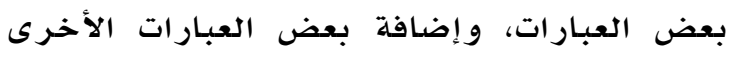
التي تم اقتراحها بواسطة إثنين من المحكمين.

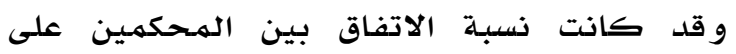

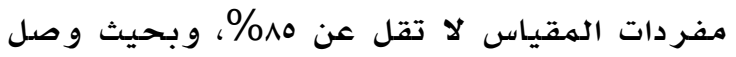
عدد العبارات إلى هev عبارة.

ثبات الاستبيان: تم حساب ثبات استبيان أساليب

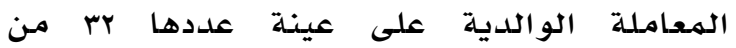

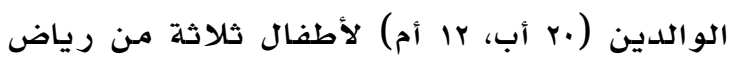

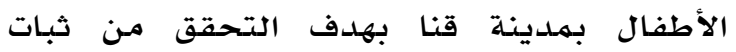

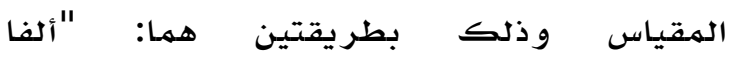

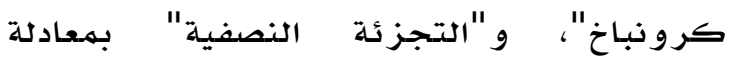

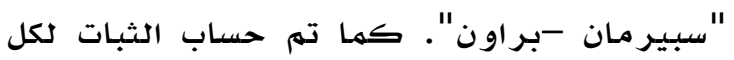

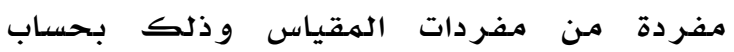

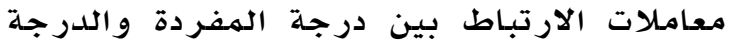

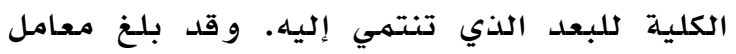

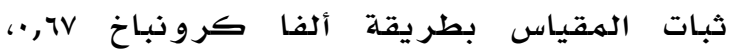

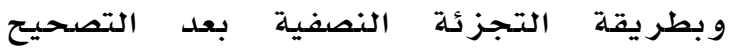

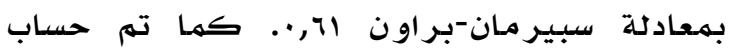
الاتساق الداخلي لمفردات المقياس كما هو مبين

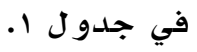

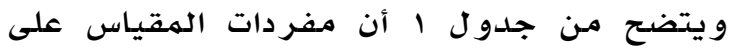

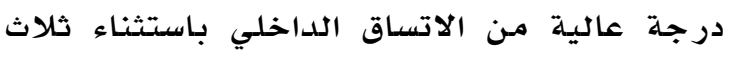

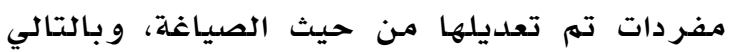

الوالدية و أنواعها وكذلك أساليب قياسها. و قد

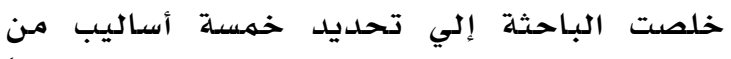
أساليب المعاملة الوالدية وهي الأكثر شيوعاً الدال

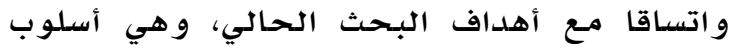

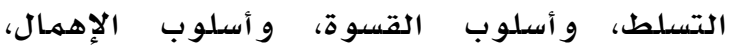
و أسلوب الديمقر اطية، و أسلوب التقبل.

ويقصد بأسلوب التسلط فرض الأب أو الأم رأيه على الطفل و والوقوف أمام رغباته و وتهديده

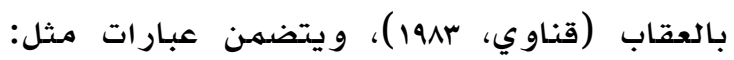

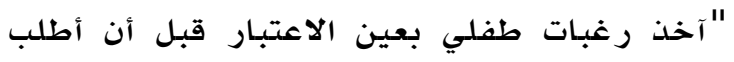

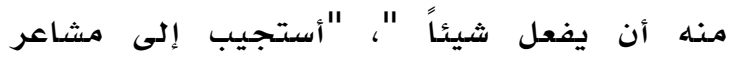

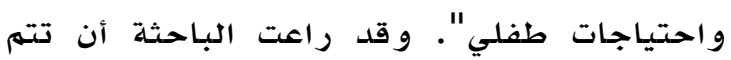

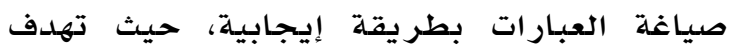
الباحثة أن يعتاد المربون والقائمون على تربية

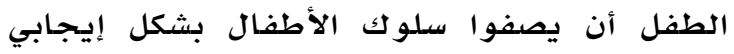

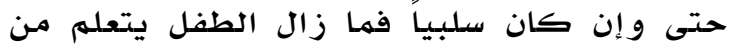

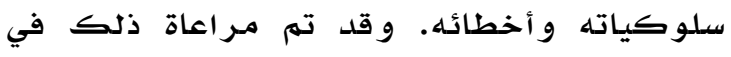
التصحيح. أما أسلوب القسوة فيقصد بهانه استخدام أساليب العقاب البدني و التهديد بالضرب التهاب في حال

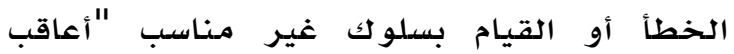

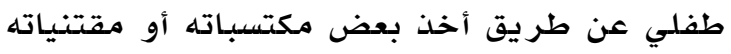

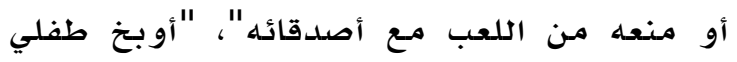

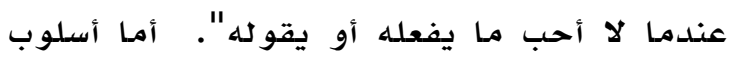
الإهمال فيقصد به عدم تشجيع أو إثابة الطفل

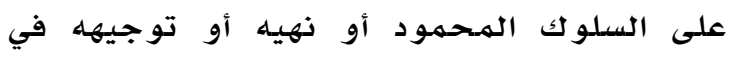

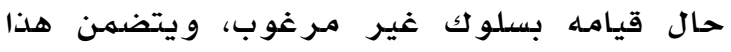

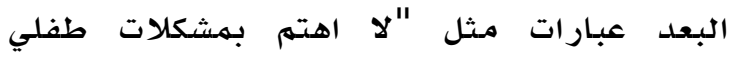

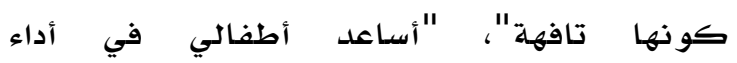

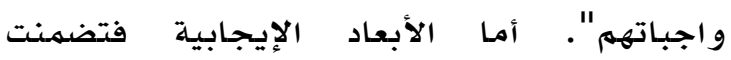

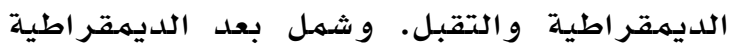
عبارات مثل "أستشير أطفالي في الأمور التي والتهي

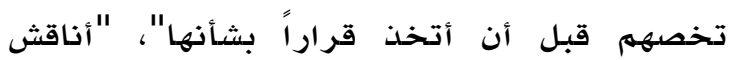

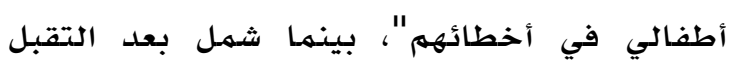

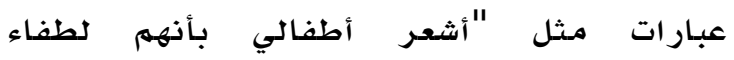
و محبون"، "أمتدح تصرفات أشعر أطفالي أمام لطفاء الأخر ين" - أوحيون" ويطلب في هذا الاستبيان من أحد الوالدين

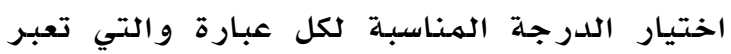

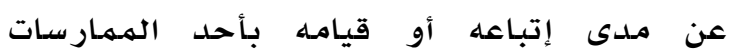

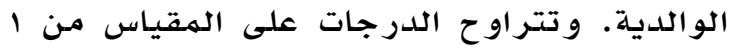


الطفل لا يقوم بطرح أسئلة تنهم عن حبـ الوستهاء

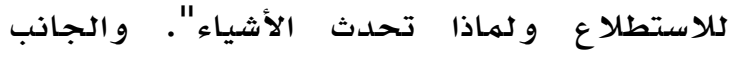
العددي و الرياضي و يحتوي على عبارات مثل "لاتل يتهكن الطفل من تصنيف الأشكال المتشابهة إلى ولى ولى

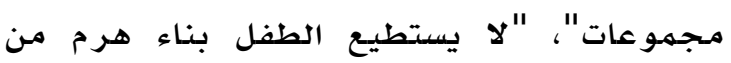

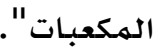

و يعد القصور في أي جانب منهما مؤشراً على تصلى

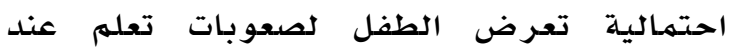

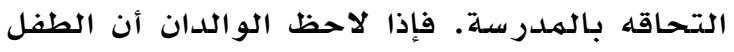
يعاني من قصور في الجانب اللغوي فإن الطفل

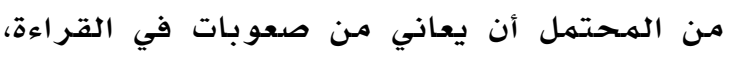

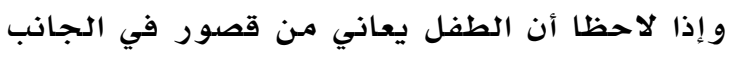

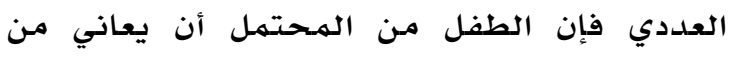

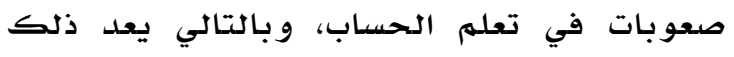

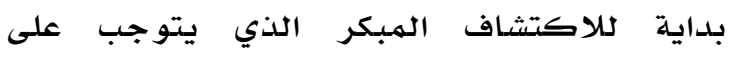

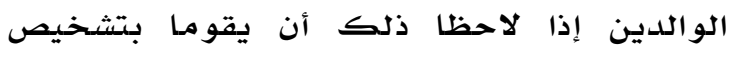

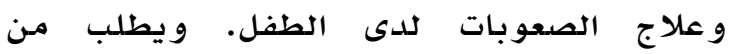

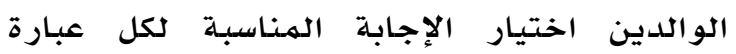

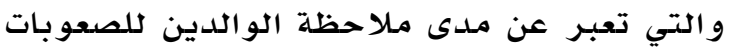

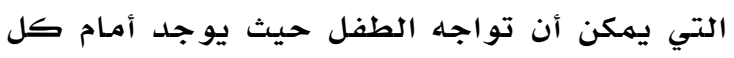

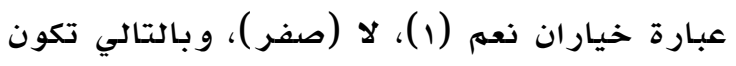

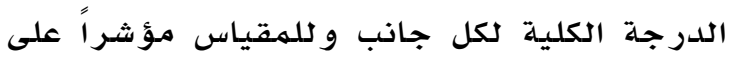

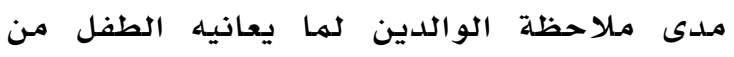

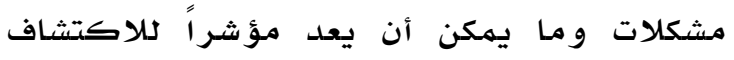

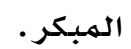

صدق المقياس: تم عرض مفردات المقياس على

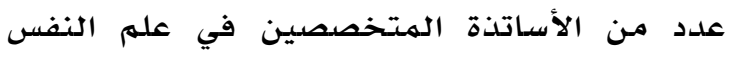

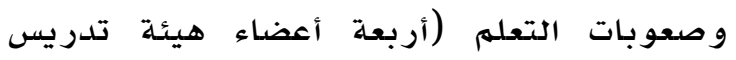
بكلية التربية بجامعة جنوب الوادي بقنا، وأحد

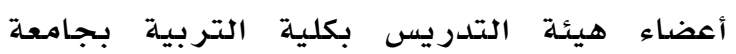

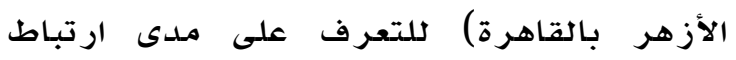

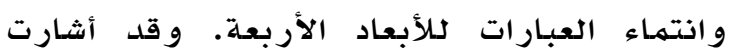
نتائج التحكيم إلى حذف بعض العبارات وتعديل البعض الأخر حيث كانت نسبة الاتفاق بين

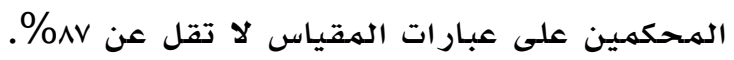

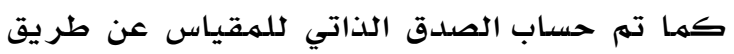

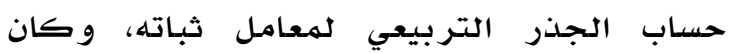
مقدار الصدق الذاتي للمقياس 91 ,•.

ثبات المقياس: طبق المقياس بمسـاعدة عينة من أو لياء أمور الأطفال في ثلاث روضيات الهيات مختلفة
يصبح المقياس صالحاً لتطبيقه في البحث الحسالي

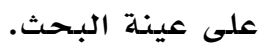

جدول

نتائج حساب الاتساق الداخلي لمفردات مقياس أساليب المعاملة الوالدية

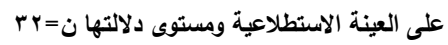

\begin{tabular}{|c|c|c|c|c|}
\hline التجزئة & ثبات & ثبات المقاييس & المفردات & رقم \\
\hline$\cdot$, TV & $\cdot, 74$ & أسلوب التسلط & 15 & 1 \\
\hline$\cdot, \times)$ & $\cdot, \times 1$ & اسلوب القسوة & ir & r \\
\hline • ג & $\cdot, \leqslant 9$ & أسلوب الإهمال & $\wedge$ & $r$ \\
\hline$\cdot, V Y$ & $\cdot, \times 4$ & ألسيقراطية & 15 & $\varepsilon$ \\
\hline .,07 & 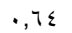 & أسلوب التقبل & 1. & 0 \\
\hline
\end{tabular}

ع. مقياس الاكتشاف المبكر لصعوبات التعلم من

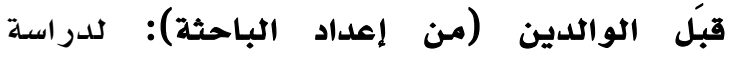

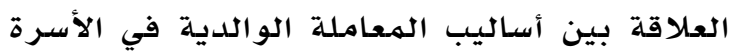
و الاكتشاف المبكر لصعوبات التعلهم لدى الطفل، ظهرت الحاجة إلى استخدام أو تصميهم استبيان

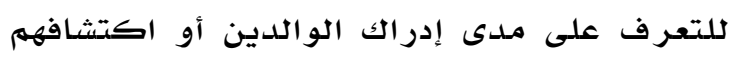

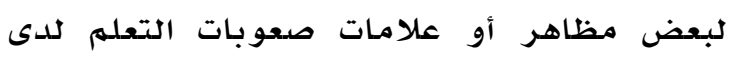
أطفالهم. و ولتحقيق هذا الهدف روجعت بعض اوض

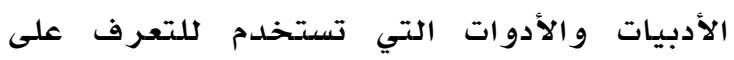

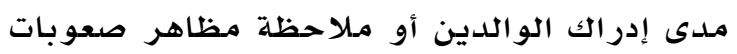

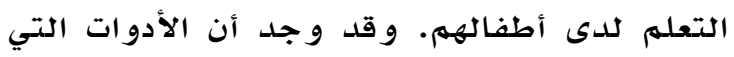
تستخدم لهذا الغرض هي مقاييس أو اختبارات للتشخيص أو الاكتشاف المبكر لصعوبات التعلهم

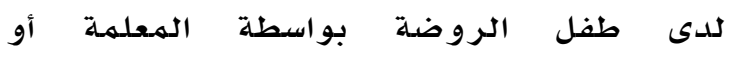

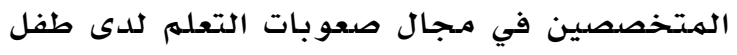
الروضدة، ولهم توجد أداة للتعرف على مدى إدى إدراك الك اله

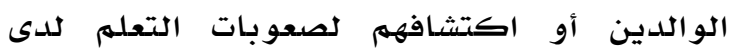

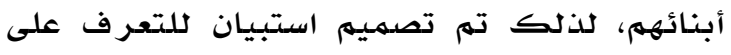
مدى اكتشاف صعوبات التعلهم لدى أطفالهم. يهدف هذا الهقياس إلى التعرف على مدى قدرة الوالدين على مـلاحظة أي قصور يمكن أن يعاني

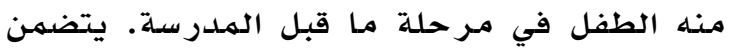

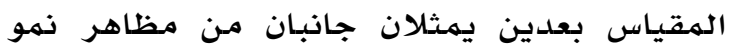
الطفل على الوالدين مـلاحظتهما ومتابعة النهمو فيهما. هذان البعدان هما الجانب اللغوي والجانب العددي ويحتوي على عبارات منها على سبيل

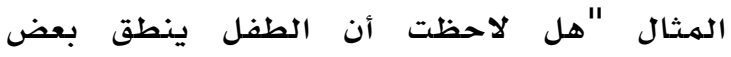

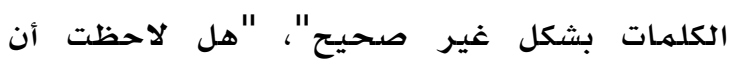


للتحقق من صححة الفرض الأول: تم حساب معاملات الارتباط بين جانبي صعوبات التعلهم

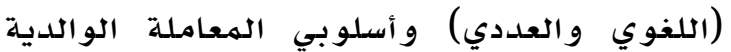

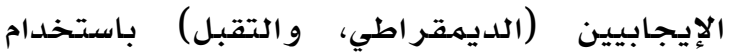
معامل ارتباط بيرسون. وقود أوضحت النتائج و جود علاقة ارتباطية موجبة ذات دلالة إحصدائية

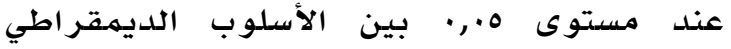

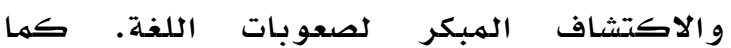
أوضحت النتائج أيضا وجود علاقة ارتباطية موجبة ذات دلالة إحصائية عند مستوى ه., بـ بين أسلوب التقبل و والاكتشاف المبكر ل لصعوبات اللغة. بينما أوضحت النتائج عدم وجود علاقة ذات دلالة إحصائية بين أي من من الأسلوب الديمقر اطي و أسلوب التقبل من جهة، و اكتشاف ما يمكن أن يعانيه الطفل من صعوبات عددية. ويمكن تفسير هذه النتيجة أن أسلوب المعاملة

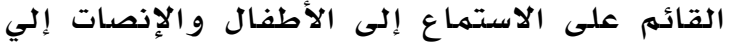

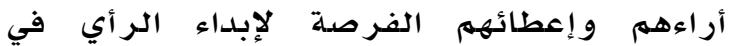
الأمور التي تخصهم أو تتعلق بالأسرة والتعبير

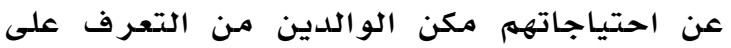

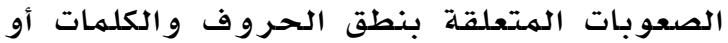
تكوين الجمل كما في جدول r. بينما لهم يتمكن الوالدين من اكتشاف الصعوبات المتعلقة بـالعدد لهدي

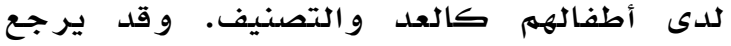
ذلك إلى أن مهارات العد والحساب أكثر تعقيدا

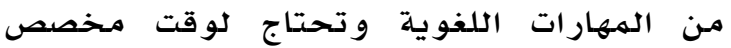
يجلس فيها الوالدين مـع الطفل لدراسـة ومتابعـة مهار ات الحساب التي يدرسونها في الرووضدة.

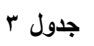

معاملات الارتباط بين أساليب المعاملة الوالاية الإيجابية والاكتثاف المبكر

\begin{tabular}{|c|c|c|c|c|}
\hline \multicolumn{5}{|c|}{ لصعويات التعلم ن=^^ } \\
\hline \multicolumn{2}{|c|}{ أسلوب التقبل } & \multicolumn{2}{|c|}{ الأسلوب الايمقراطي } & \multirow{2}{*}{ مظاهر الاكتثناف الوالدية } \\
\hline مستوى & معامل & 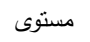 & معامل & \\
\hline الدلالة & الارتباط & الدلالة الد & الارتباط & المبكر \\
\hline$\cdot, .0$ & $\cdot, r)$ & $\cdot, .0$ & $\cdot, r 9$ & الجانب اللغوي \\
\hline غبر دالة & $\cdot, .9$ & غير دالة & $\cdot, 11$ & الجانب العددي \\
\hline
\end{tabular}

الفرض الثاني: توجد علاقة ارتباطية سالبة ذات دلالة إحصائية بين أساليب المعاملة الوالدية

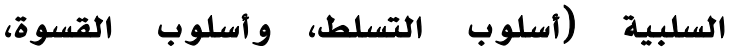
و أسلوب الإهمال) والاكتشاف المبكر لـعوبات
بمحافظة قنا خلال شهر يونيو rاיبr وذلك للتحقق من ثبات المقياس حيث بلغ حجم العينة rr (II أب، أب أم)). و للتحقق من ثبات الهقيات الهقياس

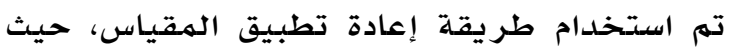
تم تطبيق الهقياس بواسطة الباحثة على أحد الوالدين بعد عقد عدة لقاءات معهم وتعريفهم

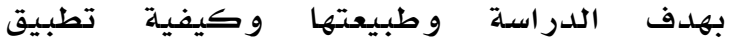

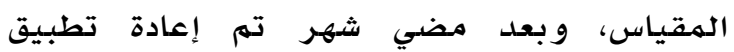
المقياس عليهم، وبحساب معامل الارتباط بين

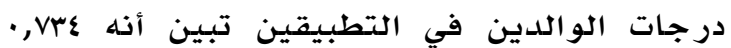

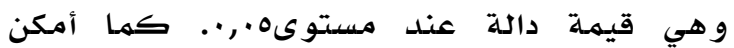
الاستدلال على الاتساق الداخلي بحسـاب معاملات

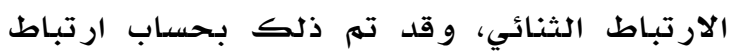
درجة كل عبارة بالدرجة الكلية للمقياس. وقد

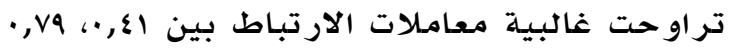
وهي قيهم دالة عند ه., •، بينما تم حذف العبارات

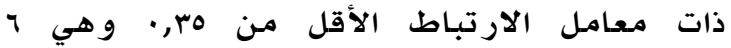

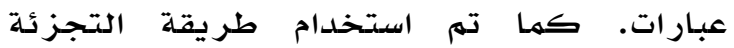
النصفية و ذلك بحساب معامل الارتباط بين

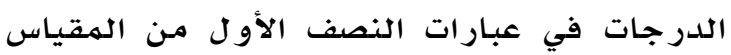
للعبارات من ا-r| ودرجاتهم في عبارات النصف

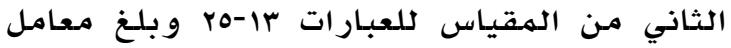

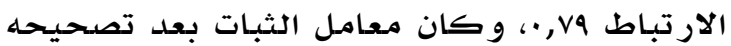
بمعادلة سبير مان-بروان اير,“، وبذانك يكون

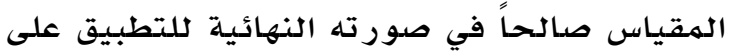
عينة الدر اسلة.

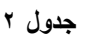

الاتساق الأخلي لمفردات مقياس الاكتثاف المبكر لصعويات التعلم من قبّل

\begin{tabular}{|c|c|c|c|c|}
\hline التجزئة النصفية ثبات & معامل ثبات & ثبات الأبعاد & المفردات & رقم \\
\hline 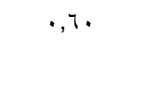 & $\cdot, 09$ & اللغوي & Ir & 1 \\
\hline$\cdot,(v)$ & $\cdot, V_{1}$ & العددي & $1 T$ & $r$ \\
\hline
\end{tabular}

\section{النتائج والمناقشة}

الفرض الأول: توجد علاقة ارتباطية موجبة ذات دلالة إحصائية بين أساليب المعاملة الوالدية الإيجابية (الأسلوب الديمقراطي، أسلوب التقبل) والاكتشاف المبكر لصعوبات التعلم في مرحلة ما قبل المدرسة من قبل الوالدين 
يمكنها من خلال هذه العلاقة الحميمة اكتشاف أي مشكلة أو صعوبة يمر بها بها الطفل. وريكون

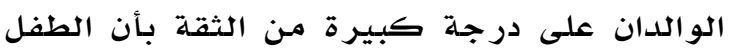

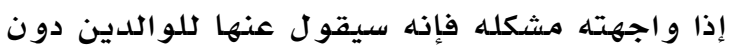
خوف، وعلى يقين بأنهما سيقدمان لله الهساعدة لحل هذه الهشكلة.

ويمكن تفسير هذه النتائج بأن أسلوب الهعاملة

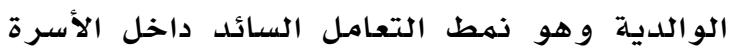
يحدد كيف يسلك الوالدين مـع الطفل وكيف

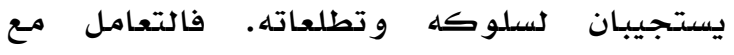
الطفل بالتوبيخ والعقاب يجعله يحجه عن ئن التواصل مـع الوالدين بشكل يمكنهـم من اكتشاف

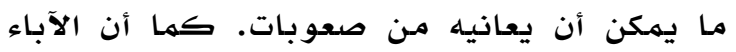
والأمهات ذذوي الأساليب التسلطية يكوذون أقل

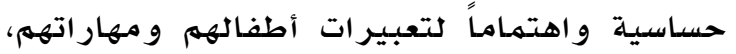

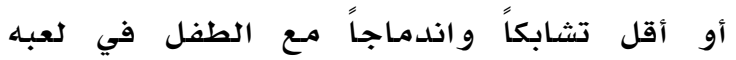
وأنشطته اليومية والحياتية، كما في أسلوب

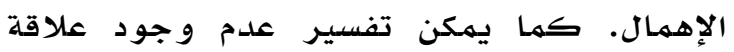
ارتباطية بين أسلوب الهعاملة الوالدية و الكتشاف

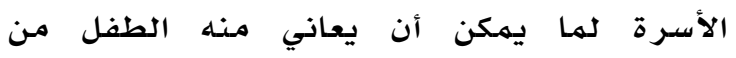
مؤشرات على وجود صعوبات في الجانب العددي

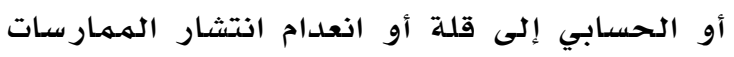

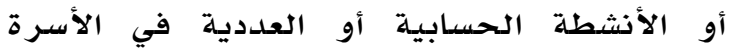

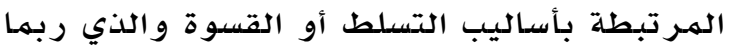
يعود إلى طبيعة و مستوى الأسر في عينة البحث. وتتفق نتائج الفرضين الأول و الثاني مـع دراسـة جانجوا ووول و كايل ( ) Janjua, Woll \& Kyle,

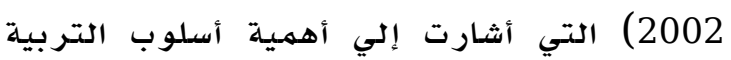

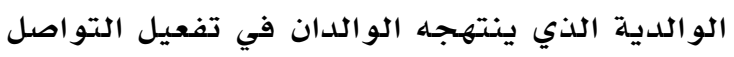

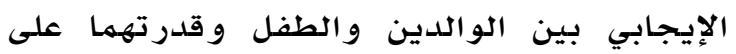
اكتشاف ما يمكن أن يواجـه الطفل من مشكلات الطين

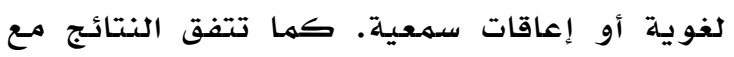

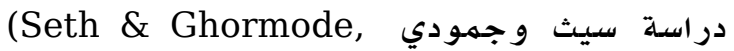
(2013 التي أكدت على أن أسلوب المعاملة
التعلم في مرحلة ما قبل المدرسة من قبل الوالدين

للتحقق من صحمة الفرض الثاني حسبت معاملات الارتباط بين جانبي صعوبات التعلهم (اللغوي

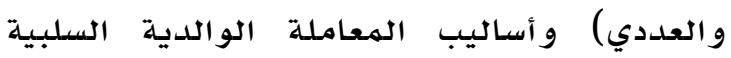

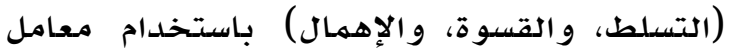

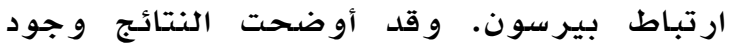

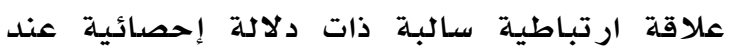
مستوى ه.,• بين أسلوب التسلط والاكتهاف إكافه

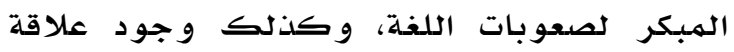

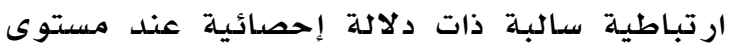
๑., بين أسلوب القسوة والاكتشاف الهبكر

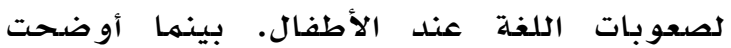
النتائج عدم وجود علاقة ذات دلادلة إحصائية بين أولن

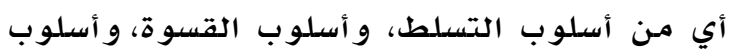
الإهمال من جهة واكتشاف مـا يهكن أن يعانيه

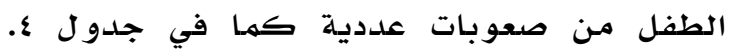
ويمكن تفسير هذه النتيجة بأن الأسر التي تتبـع الأسلوب التسلطي و الذي يتر تب عليه طاعة عمياء

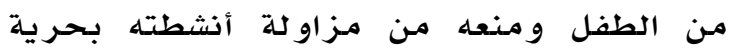

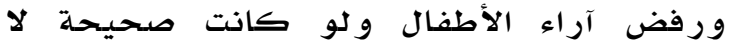
يمكِّن الوالدين من اكتشاف ما ما يعانيه الطفل من الطفال مشكلات في اللغلة أو استخدام للكلمات والجمل الجمل.

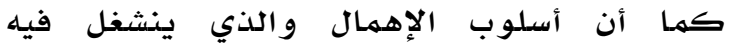

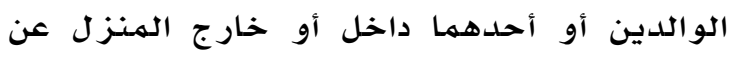
طفله أو لا يكتر ث بشؤونه أو لا يبالي بتربيته

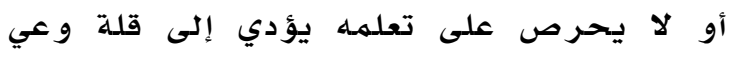
الأهل بالمشكلات أو مظاهر صعوبات التعلهم التي يعاني منها الطفل.

و عليه فإن الأسرة التي تتعامل مـع أطفالها

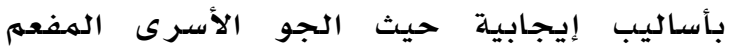

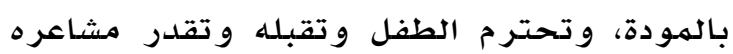
و تشركه في مناقشة أمور تخص الأسرة وتعطيه

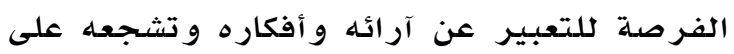
ذلك، بعيدا عن التسلط و القسوة والإهمال،

جدول

معاملات الارتباط بين أساليب المعاملة الوالدية السلبية والاكتثاف المبكر لصعويات التعلم ن=ی

\begin{tabular}{|c|c|c|c|c|c|c|}
\hline \multicolumn{2}{|c|}{ أسلوب الإهمال } & \multicolumn{2}{|c|}{ أسلوب القسوة } & \multicolumn{2}{|c|}{ أسلوب التسلط } & \multirow{2}{*}{ مظاهر الاكتثاف المعاملة الوالدية } \\
\hline مستوى الدلالة & معامل الارتباط & مستوى الدلالة & معامل الارتباط & مستوى الدلالة & معامل الارتباط & \\
\hline غير دالة & $\cdot, 11-$ &., .0 & $\cdot$, YO- & $\cdot, .0$ & $\cdot, Y)-$ & الجانب اللغوي \\
\hline غير دالة & $\cdot, 11-$ & غير دالة & $\cdot, \cdot \vee-$ & غير دالة & $\cdot, 0$ & الجانب العددي \\
\hline
\end{tabular}


من مشكلات للتكيف مـع أسرهم و أقرانهم

و ممهارسلة ما يفضلونه من هوايات.

$$
\text { المراجع }
$$

\section{References}

أبو مرق، جمال؛ أبو عقيل، إبراهيم (r.r). أساليب التنشئة الوالدية و علاقتها بالحالة الهزاجية لدى طلبة جامعة الخليل بالضفة الغربية فلسطين، مجلة جامعة الأقصى، .1 1 .

الفرا، إسماعيل صالح (0.ب). التشخيص المبكر

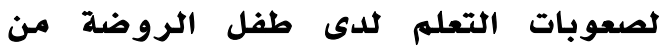
وجهه نظر التربية الخاصة. مؤتمر التربية

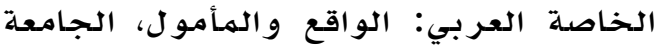

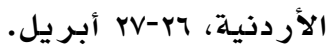

السرطاوي، عبد العزيز؛ القريوتي، يوسف

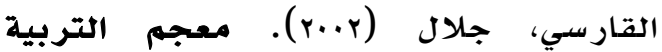
الخاصة. دبي: دار القلهم للنشر والتوزيع. السيد، فتحي؛ السعيد، حليهم (194Y). سيكو لوجية الأطفال غير العاديين واستراتيجيات التربية الخاصة، طץ، الكويت: دار القلهم.

الشخص، عبد العزيز؛ عثمان، تهاني؛ ومحمهد،

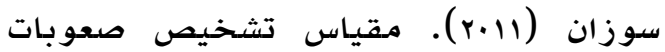

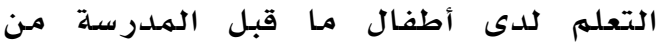
وجهة نظر المعلمات والأمهات. مجلة كلية اهلية

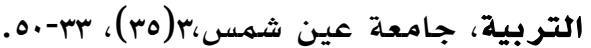
بدر الدين، خديجة محمدد (عا.r). فاعلية برنامـج

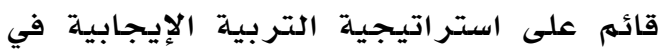
تنمية تقدير الذات لدى أطفال الروضدة ذوي صعوبات التعلهم. مـجلة الدراسات التربوية

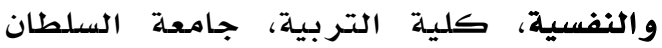

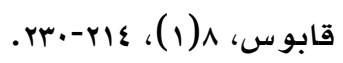

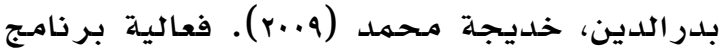
لتهيئة طفل الرو ضدة للقر اءة و الكتابة ودوره في التغلب على بعض صعوبات التعلهم. رسالة دكتور اه غير منشورة، كلية التربية، جامعة جنوب الوادي، جمهورية مصر

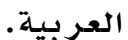

الوالدية المتبع في الأسـرة يرتبط بمدة قدرة الأسرة على حل مشكلات الأطفال الأكاديمية في

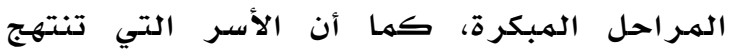
أساليب معاملة إيجابية أكثر قدرة على توجيه

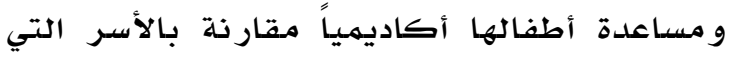
تنتهج أساليب تسلطية، حيث يرغب الوالدين في الاستماع إلى طفليهما كما يبديان رغبة أكبر في حضور الاجتماعات مـع المعلمين بشكل دوري. و بالتالي فإنه يمكن إجمال نتائج البحث الحالي

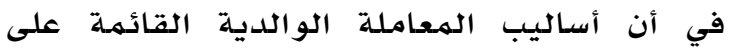

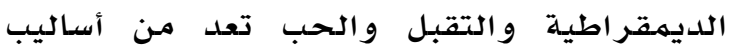
المعاملة السوية في تنشئة الطفل والذي يترتب على ممارستها داخل الأسرة نتائج إيجابية في فئه مساعدة ودعم تعلم الطفل وإتاحة الفرصة لكه

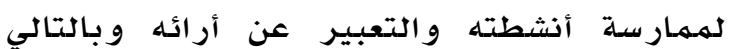
التعرف على ما يمكن أن يطرأ عليه مـن مظاهر

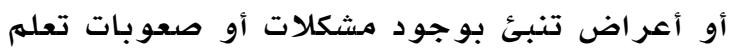
مستقبلية. توصيات البحث

في ضوء نتائج البحث الحالي التي أوضحت

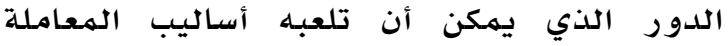

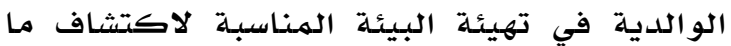
يمكن أن يعاني منه الطفل مـن مشكلات، فإنه يمكن إجمال التوصيات فيما يلي:

ا. توعية الوالدين وتقديم البـرامج الهناسبـة

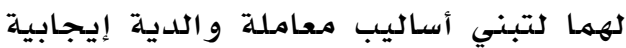

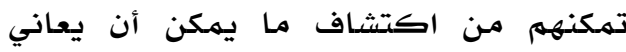
منه الأطفال من صعوبات في التعلم في مر احل لاحقة. r. العمل على توطيد العلاقة والتعاون بين

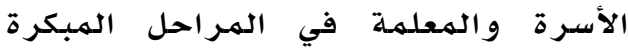
للتعرف أكثر على الخصائص النمائية للطفل و بالتالي توفير أساليب المعداملـة الوالدية المناسبـة له. r. توفير برامب مناسبة في مرحلة ما قبل

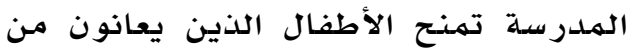
مشكلات تعلم نمائية مزيدا من الثقة في

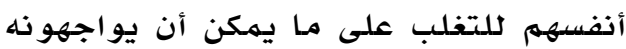




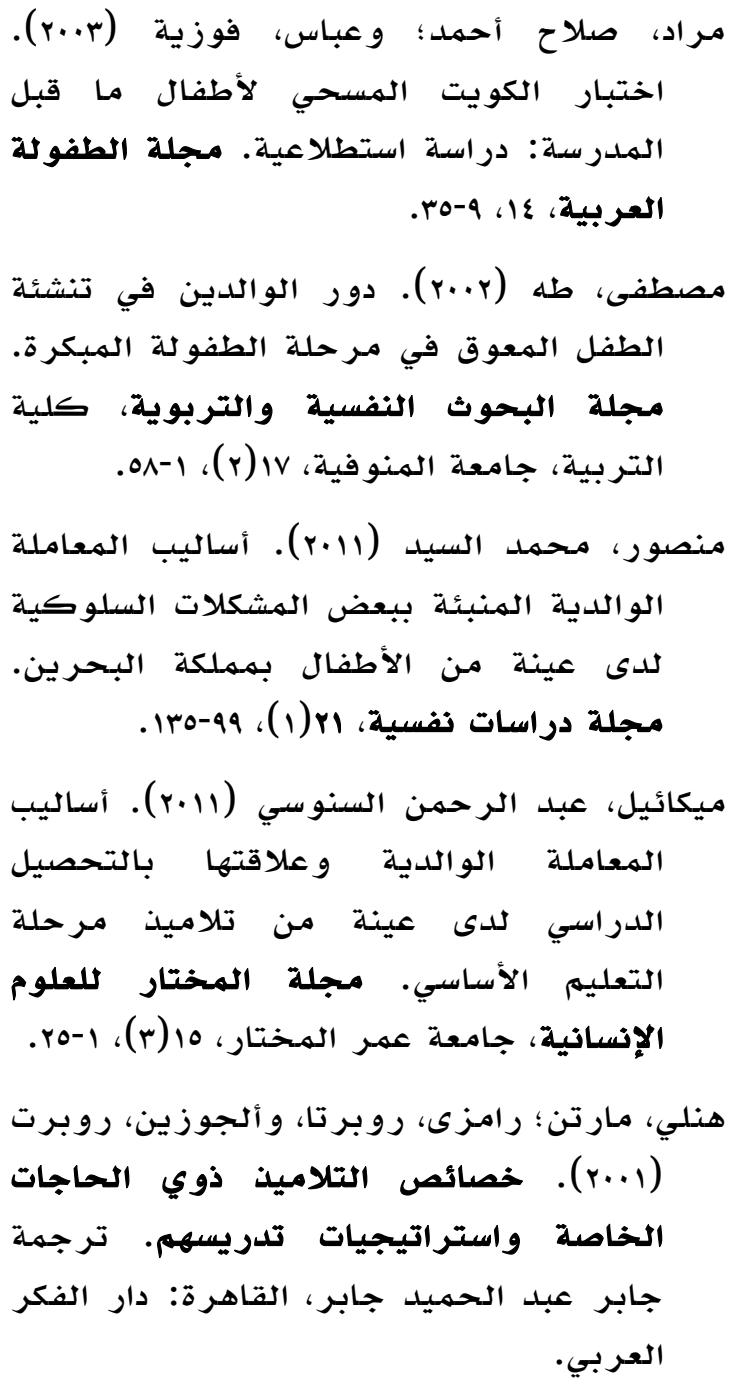

Guerin, W., Gottfried, W., Oliver, H., Thomas, W. (1994). Temperament and school functioning during early adolescence. Journal of Early Adolescence, 14, 200-225.

Hart, C.H., Newell, L.D., \& Olsen, S.F. (2003):

Parenting skills and social communicative competence in childhood. In J.O. Greene \& B.R. Burleson (Eds), Handbook of communication and social Interaction Skill (pp. 753-797). Mahwah. NJ: Erlbaum.

Janjua, F., Woll, B., \& Kyle, J. G. (2002). Effects of parental style of interaction on language development in very young severe and profound deaf children. International Journal of Pediatric Otorhinolaryngology, 64, 193-205

Robinson, C., Mandleco, B., Olsen, F., \& Hart, H. (1995). Authoritative, authoritarian, and permissive parenting practices: Development of a new measure. Psychological Reports, 77, 819-830.
حمادة، و وليد (.1.). سوء معاملة الأبناء

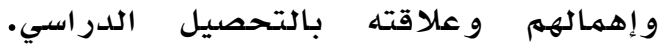
مجلة جامعة دمشق، المجلد דr، هrY-rVI.

سليمان، السيد عبد الحميد (ب..r). صعوبات التعلم، تاريخها، مفهومها، تشخيصها، علاجها. القاهرة: دار الفكر العربي.

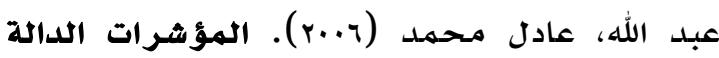

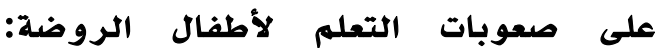
دراسات تطبيقية. القاهرة: دار الرشاد.

عواد، أحمد (1998). التعرف المبكر على صعوبات التعلم النمائية للى الأطفال في مرحلة ما

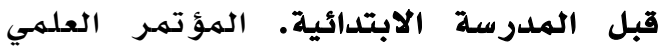

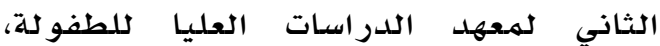

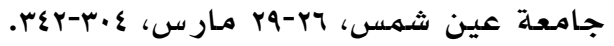
فاضل، فهمي حسان (.1.r). سوء معاملة أطفال الشوارع و أثرها في مفهوم الذات و السلوك كه

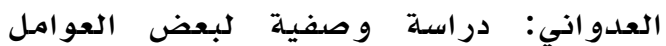
المـرتبطة بالظاهرة. مجلة الطفولة العربية،

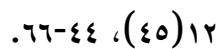

فايد، جمال عطية (r.v) إماليب المعاملة الوالدية كمتغير وسيط بين الخصائص المزاجية والمشكلات السلوكية لدى أطفال

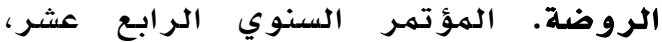

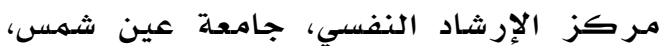

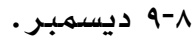

قناوي، هلى محمد (1911). الطفل - تنشئته وحاجاته. القاهرة: مكتبـة الأنجلو الهصرية.

كامل، مصطفي (199V). اختبار القدرة العقلية العامة. القاهرة: مكتبـة الأنجلو المصريلة.

كوافحة، تيسير مفلح؛ عبد العزيز، عمـر فواز

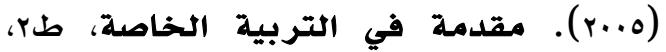

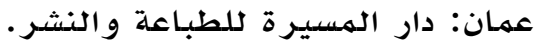

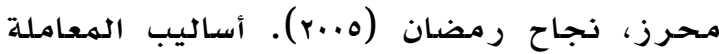
الوالدية و علاقتها بتوافق الطفل الاجتماعي

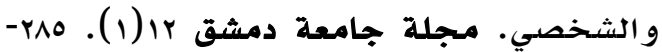
.rYs 
Seth, M. \& Ghormode, K. (2013). The impact of authoritative parenting style on educational performance of learners at high school level. International Research Journal of Social Sciences. 2(10), 1-6.

Wenar, C. \& Kerig, P. (2005). Developmental psychopathology from Infancy through adolescence. Mc Graw-Hill, Ny. 